\title{
La escena artística en Quito a inicios del siglo XX. Exposiciones, prensa y público*
}

\author{
The art scene in Quito at the beginning of the twentieth century. \\ Exhibitions, the press and the public \\ A cena artística em Quito no começo do século XIX.
Exposições, imprensa e público
}

Trinidad Pérez Arias

Universidad Andina Simón Bolívar, Sede Ecuador trinidad.perez@uasb.edu.ec

DOI: http: / / dx.doi.org/10.29078/rp.v0i48.699

Fecha de presentación: 23 de febrero de 2018

Fecha de aceptación: 17 de mayo de 2018

Artículo de investigación

* Una versión muy preliminar de las ideas que se desarrollan en este artículo fue presentada en una ponencia inédita en las Jornadas Internacionales de Historia del Arte y la Arquitectura (HISTAA) en la Universidad de Cuenca, en noviembre de 2015. En un segundo momento este artículo fue elaborado gracias al fondo de investigaciones de la Universidad Andina Simón Bolívar, Sede Ecuador (UASB-E) en 2016 y versiones de él presentadas en el evento académico de la exposición "Academias y arte en Quito" en el Museo de Arte Colonial, en junio de 2017, y en el Encuentro de Historia del Arte: Diálogos en torno al arte moderno ecuatoriano, organizado por la Universidad Central del Ecuador, en julio del mismo año. Agradezco a Luis Esteban Vizuete por el apoyo en la investigación documental realizada para este proyecto y a los lectores ciegos de este dossier, cuyas observaciones y comentarios han contribuido a mejorar sustancialmente este artículo. 
RESUMEN

Este texto explora el papel que desempeñaron las exposiciones de arte, la prensa y el público, considerados como elementos de la organización de un sistema artístico moderno y como factores de la dinamización de la escena artística en Quito, entre 1904 y 1918. Se analiza, en primer lugar, el papel de la Escuela de Bellas Artes en la expansión de la producción artística desde su refundación en 1904. Seguidamente, se considera la relación entre las artes visuales, la escena pública, la instalación del Estado liberal y su proyecto de construcción de una sociedad moderna. Finalmente, se identifican las tensiones que este proceso cultural experimenta cuando nuevos actores entran en escena hacia 1918.

Palabras clave: historia del arte, historia cultural, historia latinoamericana, modernidad, Escuela de Bellas Artes, escena artística, bellas artes, exposiciones, prensa, Quito, siglo XX.

ABSTRACT

This text explores the role that art shows, the press, and the public played in organizing a modern art system and as the driving forces behind the art scene in Quito between 1904 and 1918. First of all, it examines the role played by the Fine Arts School in expanding art production, following its reestablishment in 1904. Then it considers

the relationship between the visual arts, the public stage, and the establishment of a liberal State and its plan to build a modern society.

Finally, it identifies the tensions sustained by this cultural process when new stakeholders arrived on the scene around 1918.

Keywords: Art history, cultural history, Latin American history, modernity, School of Fine Arts, art scene, fine arts, exhibitions, press, Quito, twentieth century

RESUMO

Este artigo faz uma análise do papel das exposições da arte, a imprensa e o público vistos como elementos da organização de um sistema artístico moderno, e como fatores de dinamização da cena artística em Quito, entre 1904-1918. Analisa-se, em primeiro lugar, o papel da Escola de Belas Artes na expansão da produção artística desde sua refundação em 1904. Em segundo lugar, estudam-se as relações entre artes visuais, cena pública e a consolidação do estado liberal e seu projeto de construção de uma sociedade moderna. Finalmente, identificam-se as tensões desse processo cultural quando novos atores entram em cena para 1918.

Palavras chave: História da arte, história cultural, história da América Latina, Escola de Belas Artes, cena artística, beijas artes, exposições, imprensa, Quito, século XX. 


\section{INTRODUCCIÓN}

Al examinar detenidamente las obras expuestas en el Salón de Pintura fácilmente echamos de ver... el preludio de una cierta escuela que va formándose de los diversos componentes presentados en otras exposiciones, ya por algún profesor de nuestra Escuela Nacional, ya por algún compañero venido de otro ambiente...

Javier Andrade ${ }^{1}$

En este texto que refiere a la III Exposición Anual de Bellas Artes, celebrada en Quito en agosto de 1915, Javier Andrade dirige nuestra atención a un momento de dinamización de la escena artística en la ciudad y menciona algunos de los elementos que lo hicieron posible -la educación formal, con los aportes del profesorado extranjero y de las becas al exterior; el efecto de las exposiciones artísticas-, que indican que, de hecho, se trataba de un momento de configuración de un sistema artístico moderno. Según Oskar Kristeller y Larry Shiner, un sistema artístico estaría constituido por condiciones institucionales, intelectuales y económicas que posibilitan que un cierto tipo de arte se desarrolle en un momento y lugar. ${ }^{2}$ En él, "los conceptos regulativos, los ideales del arte y los sistemas sociales del arte son recíprocos: los conceptos y los ideales no pueden existir sin un sistema de prácticas e instituciones, así como las instituciones tampoco pueden funcionar sin una red de conceptos e ideales formativos". ${ }^{3}$ Se entiende el arte como parte de un entramado social y no como un universal abstracto que existe más allá de las condiciones históricas que le hacen posible.

El establecimiento de sistemas artísticos modernos fue consecuencia de los procesos de modernización de las sociedades occidentales. Respondió a la concepción ilustrada del conocimiento, que lo compartimentalizó en disciplinas para cumplir con distintas finalidades prácticas, morales y filosóficas en el mundo moderno; ${ }^{4}$ y, consecuentemente, contribuyó a la construcción de los Estados nacionales. En Ecuador, ya a fines del siglo XVIII Eugenio

1. Javier Andrade, "La tercera exposición nacional de Bellas Artes de Quito", Letras IV, n. ${ }^{\circ} 32$ (septiembre 1915): 249.

2. Larry Shiner, La invención del arte: una historia cultural (Barcelona: Paidós, 2004); Paul Oskar Kristeller, "The Modern System of the Arts: A Study in the History of Aesthetics", Journal of the History of Ideas art I, vol. 12, n. ${ }^{\circ} 4$ (octubre 1951): 496-527; II, vol. 13, n. ${ }^{\circ} 1$ (enero 1952): $17-46$.

3. Shiner, La invención del arte..., 31, nota 1.

4. Immanuel Wallerstein, Abrir las Ciencias Sociales: Informe de la comisión Gulbenkian para la reestructuración de las Ciencias Sociales (México D. F.: Siglo XXI Editores, 1999). 
Espejo habló de la necesidad de crear academias de pintura y escultura con el fin de reproducir y perpetuar los conocimientos artísticos. ${ }^{5}$ Una vez constituida la República, en la Constitución de 1835 se exigía el establecimiento de la educación artística formal. ${ }^{6}$ Se trata de un ideal de reorganización de la práctica artística que en el campo de las ideas buscaba redefinirla con el fin de superar los modelos que prevalecían desde el período colonial: separar las bellas artes de las prácticas manuales e industriales, convertir a pintores y escultores de artesanos en artistas; ${ }^{7}$ pero, también, de desarrollar un modelo de modernidad artística 'otra', adaptada a las necesidades de una élite poscolonial que necesitaba reafirmarse localmente y legitimarse a nivel global. ${ }^{8}$ Aunque el Estado demoró en establecer una academia de bellas artes hasta 1860, desde al menos 1847 se tiene noticias de diversas instituciones que ofrecieron o auspiciaron cursos basados en una pedagogía artística académica. ${ }^{9}$ Estas iniciativas estuvieron acompañadas por un corpus de publicaciones que durante la segunda mitad del siglo XIX buscaron orientar, tanto a artistas como al Estado, sobre el deber ser artístico. ${ }^{10}$

Un momento culminante en este proceso de modernización del sistema artístico fue la creación, en 1904, de la Escuela de Bellas Artes (EBA) en Quito, que no solo significó el establecimiento definitivo de la educación artística formal, sino la proyección del arte en el espacio público, a través de

5. Eugenio Espejo, Primicias de la cultura de Quito, n. ${ }^{\circ} 6$ (15 de marzo de 1792): 84.

6. Constitución de la República del Ecuador, 1835. El decreto modificatorio de 1838 lo ratificó: "Decreto Reglamentario de Instrucción Pública". En Julio Tobar Donoso, García Moreno y la Instrucción Pública (Quito: Editorial Ecuatoriana, 1940): 14.

7. Sobre los ideales políticos liberales de los artesanos en el Ecuador de mediados del siglo XIX, véase Galaxis Borja González, " 'Sois libres, sois iguales, sois hermanos' Sociedades democráticas en Quito de mediados del siglo XIX", JahrbuchfürGeschichteLateinamerikas / Anuario de Historia de América Latina 53 (2016): 185-210.

8. Véase Mary Louise Pratt, Ojos imperiales: literatura de viajes y transculturación (Buenos Aires: Universidad Nacional de Quilmes, 1997) y otros autores que buscan explicar los procesos de modernización cultural en lugares alejados de los centros de poder imperial, sin caer en esa visión que concibe a esas modernidades como incompletas o inconclusas, sino más bien, sencillamente, como "otras", marcadas por condiciones complejas de posibilidad.

9. Para una cronología actualizada de academias oficiales y privadas en el siglo XIX, véase Trinidad Pérez, "Modos de aprender y tecnologías de la creatividad: el establecimiento de la formación artística académica en Quito: 1849-1930". En Catálogo de la exposición Academias y arte en Quito: 1849-1930, Museo de Arte Colonial, abril-julio de 2017, curadoras Trinidad Pérez y Ximena Carcelén (Quito: Casa de la Cultura Ecuatoriana, CCE, 2017): 17-50, y otros artículos míos sobre el tema. Para un balance historiográfico sobre la educación artística en el siglo XIX: Alexandra Kennedy, "Del taller a la academia: educación artística en el siglo XIX en Ecuador", Procesos: revista ecuatoriana de historia, n. ${ }^{\circ} 2$ (1992): 124-125).

10. El ejemplo más relevante es Juan León Mera, Ojeada histórico-crítica sobre la poesía ecuatoriana desde su época más remota hasta nuestros días (Guayaquil: Ariel, s. f. [1868]). 
exposiciones estudiantiles anuales y la publicación de una revista institucional, la Revista de la Escuela de Bellas Artes. La participación de la institución en la organización de la Exposición Nacional del Centenario de 1909 y en el establecimiento y desarrollo de la Exposición Anual de Bellas Artes desde 1913 continuó con ese impulso. La participación de la prensa en esta dinámica fue importante para crear un público aficionado. ${ }^{11}$ Cuando se inauguró la Primera Exposición Anual de Bellas Artes, circulaban varias revistas culturales, literarias y de variedades; el diario El Comercio lo hacía desde 1906 y el diario El Día, precisamente, desde 1913. Estas publicaciones fueron plataformas para el desarrollo de un periodismo cultural que, a veces, llegó a acercarse a la práctica especializada de la crítica de arte. Exposiciones y medios interesaron a los espectadores en el devenir artístico. Fue un momento de sinergia entre proyectos institucionales, producción de ideas y de arte, prensa y recepción del público. En 1918, sin embargo, cuando ingresan nuevos actores y agentes en escena, surgen tensiones y disputas y por ello se toma a este año como el punto de cierre de este momento de aparente concordia.

Este artículo, ampliación de un esfuerzo investigativo previo, ${ }^{12}$ se pregunta: ¿Cómo la articulación entre exposiciones, prensa y su efecto en el público definió las prácticas y conceptos artísticos? ¿De qué modo contribuyó a la estructuración de un sistema artístico moderno y a la configuración inicial de una escena artística pública entre 1904 y 1918? El objeto de este artículo es explorar en estas relaciones y sus efectos en la definición de valores, en la estructuración de un sistema artístico moderno y en su legitimación en la complejidad del entramado social. ${ }^{13}$

Estudiar el arte como sistema no es solo un modo de entender el arte en sus condiciones de posibilidad sino también un enfoque metodológico que permite analizar la articulación entre distintos elementos de un sistema. Si bien este artículo se centra en un núcleo específico de relaciones, he trabajado otros aspectos también. ${ }^{14}$ Este enfoque dialoga con investigaciones realizadas alrededor de las nociones de campo de Bourdieu, por María del Carmen Oleas en relación al campo del arte contemporáneo en Quito desde

11. Kristeller, "The Modern System...", II, 44.

12. Trinidad Pérez, "La construcción del campo moderno del arte en el Ecuador, 18601925: geopolíticas del arte y eurocentrismo" (tesis de doctorado, UASB-E, 2012). http:/ / hdl.handle.net/10644/3081/TD028-TECLA-Pérez; así como otros artículos citados más adelante.

13. Kristeller, "The Modern System...", II, 35.

14. Trinidad Pérez, "Nace el arte moderno: espacios y definiciones en disputa". En Celebraciones centenarias y negociaciones por la nación ecuatoriana, coord. por Valeria Coronel y Mercedes Prieto (Quito: Facultad Latinoamericana de Ciencias Sociales, FLACSO Ecuador, 2010), 23-75; véase también Pérez, "La construcción del campo...". 
1960 o sobre la agencia cultural en la misma década por Pamela Cevallos. ${ }^{15}$ A nivel regional, el estudio sobre la configuración de la escena artística moderna tiene un referente en el libro de Laura Malosetti Costa sobre Buenos Aires, ${ }^{16}$ pero en otros países de América Latina algunos investigadores vienen trabajando sobre el tema. ${ }^{17}$ Todos estos trabajos tienen que ver con una mirada sobre el arte en las condiciones inmediatas de posibilidad, las de la institución arte, que son las que le permiten articularse al tejido social.

\section{LAS PRIMERAS EXPOSICIONES Y LA FORMACIÓN DE PÚBLICOS DE AFICIONADOS: 1904-1909}

La fundación de la Escuela de Bellas Artes (EBA) en 1904 se dio en el contexto de la instalación del Estado liberal luego de la revolución de 1895, que entre otros objetivos tuvo el de fortalecer la educación en los distintos niveles y con ello continuar con la construcción de un Estado nacional moderno y progresista. ${ }^{18}$ La EBA fue una de las instituciones que, creadas por García Moreno (1860-1875) y clausuradas luego de su asesinato, se reabrieron en medio del entusiasmo de las reformas liberales, que dieron impulso a la educación en las artes por su identificación con la civilización y el progreso, valores que permitirían al país ingresar de lleno en la modernidad. La educación artística no podía, por tanto, reducirse a la enseñanza, sino que debía acercarse a quienes, finalmente, lo iban a valorar y consumir, sus públicos, quienes también

15. María del Carmen Oleas, “El campo del arte en Quito, configuración y cuestionamientos (1966-2008)" (tesis de doctorado, FLACSO Ecuador, 2018); Pamela Cevallos, La intransigencia de los objetos: la Galería Siglo XX y la Fundación Hallo en el campo del arte moderno ecuatoriano [1964-1979] (Quito: Fundación Museos de la Ciudad / Centro de Arte Contemporáneo, 2013).

16. Laura Malosetti Costa, Los primeros modernos: Arte y sociedad en Buenos Aires a fines del siglo XIX, Buenos Aires (Buenos Aires: FCE, 2007).

17. Véase, por ejemplo, Josefina de la Maza Chevesich, "Por un arte nacional: pintura y esfera pública en el siglo XIX chileno". En Ciencia-mundo: orden republicano, arte y nación en América (Santiago: Editorial Universitaria, 2010), 279-318; Ruth Acuña, "El papel periódico ilustrado y la génesis de la configuración del campo artístico en Colombia" (tesis de maestría, Universidad Nacional de Colombia, sede Bogotá, 2002); y, Ruth Acuña, "Alberto Urdaneta: coleccionista y artista” (Bogotá: Universidad Nacional de Colombia, 2010).

18. Sobre la Escuela de Bellas Artes (EBA), véase Mireya Salgado y Carmen Corbalán de Celis, "La Escuela de Bellas Artes en el Quito de inicios del siglo XX" (Quito: Instituto de la Ciudad, 2012); Pérez, "La construcción del campo..."; y Trinidad Pérez, "La Escuela Nacional de Bellas Artes y el arte moderno en Quito a inicios del siglo XX". En Alma mía. Simbolismo y modernidad. Ecuador 1900-1930, ed. y coord. por Alexandra Kennedy Troya y Rodrigo Gutiérrez Viñuales (Quito: Hominem Editores / Museo de la Ciudad / Centro Cultural Metropolitano, 2013), 114-122. 
debían ser formados estéticamente a través de la observación guiada por una crítica cada vez más especializada. Los medios a través de los cuales la EBA buscó poner en marcha estos objetivos fueron las exposiciones escolares anuales y la Revista de la Escuela de Bellas Artes, ${ }^{19}$ dos mecanismos característicos de toda academia de bellas artes. Su participación como organizadora, convocante y expositora en la gran Exposición del Centenario en 1909 selló su lugar predominante en la escena cultural de la ciudad. Miremos, a continuación, cómo se fueron articulando estas acciones en este primer momento.

A los pocos meses de su inauguración, la institución llevó a cabo la primera exposición estudiantil. Al finalizar cada año escolar, y luego de rendir exámenes, se instalaban los trabajos realizados por los alumnos en sus distintas asignaturas y se los ponía a disposición de los asistentes, por tres o cuatro días. ${ }^{20}$ El discurso que ofreció el director en ocasión de la inauguración de la exposición escolar de 1909 deja ver los objetivos de este tipo de eventos: "a fuerza de repetidas exposiciones, o de una permanente, se conseguirá educar el gusto del público y ganar su voluntad para toda manifestación de arte, despertando sus sentidos al análisis". Es decir, tenían un rol evaluador-medir los avances de los estudiantes y el progreso de la institución-, así como formativo -educar estéticamente al público. Y con ello, finalmente, "difundir el arte en lo posible y hacerlo amable, invitando a los recelosos a seguir la marcha de los que laboran por vocación expontánea [sic] y resuelta".$^{21}$

En agosto de 1905 circuló el primer número de la Revista de la Escuela de Bellas Artes. ${ }^{22}$ Como órgano de difusión de la academia, anunciaba las exposiciones, publicaba grabados de los estudiantes, presentaba estudios críticos sobre artistas de la historia del arte local y europea, presentaba el organigrama de la institución y, con ello, llevaba a cabo labores decisivas: socializar

19. La EBA fue inaugurada en el Teatro Sucre la noche del 24 de mayo de 1904.

20. Tanto la Escuela Democrática Miguel de Santiago como la Escuela de Pintura de Cuenca realizaron exposiciones escolares. Véase Sociedades Democráticas de Ilustración, de Miguel de Santiago y Filarmónica: Discursos pronunciados en la sesión pública de exhibición efectuada el 6 de marzo de 1852 por los miembros de las Sociedades Democráticas de Ilustración, de Miguel de Santiago y Filarmónica, en el séptimo aniversario del seis de marzo de 1845 [1. ${ }^{a}$ ed. Quito: Imprenta F. Bermeo, 1852]. Copia facsimilar, Colección Fuentes y Documentos para la Historia de la Música en el Ecuador II (Quito: Banco Central del Ecuador, BCE, 1984); La Escuela de Pintura de Cuenca: su primera exposición de dibujo, julio 30 de 1893 (Cuenca: Universidad del Azuay, 1893).

21. [Víctor Puig], "Discurso del Director de la Escuela con motivo de la repartición de premios y exposición escolar celebrada el día $1^{\circ}$ de noviembre de 1909", Revista de la Escuela de Bellas Artes III, n. 8 (3 de noviembre de 1909): 143-144.

22. Es la primera revista exclusivamente dedicada a las artes plásticas en Ecuador. En una primera etapa circuló desde agosto de 1905 hasta noviembre de 1909, con dos o tres números por año. 
con sus lectores las definiciones y valores estéticos básicos; y, en su carácter institucional, instalar a la actividad artística como a las acciones de la EBA, tanto en el imaginario social como en el de la política gubernamental.

Cuatro años más tarde, la EBA participó en la organización de la Exposición Nacional del Centenario; tanto el director como los profesores actuaron como agentes de decisión y convocantes. Adicionalmente, maestros y estudiantes expusieron sus obras. ${ }^{23}$ La Exposición siguió la estructura de las exposiciones universales del siglo XIX, en algunas de las cuales Ecuador había participado: en 1892, en la Exposición Histórica Americana en Madrid, en 1893 en la Exposición Colombina de Chicago y en 1899 en la Exposición Universal de París. ${ }^{24}$ Como aquellas, la Exposición del Centenario mostró al arte y a la ciencia como conocimientos especializados que contribuían al progreso y la civilización. De ahí la importancia que se le otorgó al Pabellón de Bellas Artes. A ese imaginario de progreso y civilización respondía, también, la visión de las artes divididas en bellas artes, artes manuales y artes industriales, que se reflejó en la organización en secciones expositivas distintas. Esta separación tenía la función pedagógica de mostrar al público que en ningún caso los diversos tipos de arte debían ser confundidos entre sí, pues cumplían distintas funciones sociales: las bellas artes fomentaban la moral y la espiritualidad, y se mostraban ajenas a la utilidad y funcionalidad cotidianas de las artes manuales e industriales. ${ }^{25}$

El Pabellón de Bellas Artes suscitó varias valoraciones críticas. Una de las más agudas fue la que ofreció César Alfonso Pástor, profesor de estética en la EBA, en "Juicio artístico de la Exposición Nacional" ${ }^{26}$ Pástor se centró, fundamentalmente, en impartir criterios para entender el arte como parte del proyecto civilizatorio de construcción de la nación y en resaltar su importancia en el desarrollo de los jóvenes. Los estudiantes de la EBA expusieron en

23. Catálogo General de los Premios Conferidos por el Jurado de la Exposición a los concurrentes al Certamen Nacional, inaugurado en la capital de la República del Ecuador el 10 de agosto de 1909 con motivo del Centenario de la Independencia Sud-Americana (Quito: Imprenta y Encuadernaciones Nacionales, 1910); Jenaro Larrea, Reglamento Oficial para la Exposición Nacional (Quito: Imprenta Nacional, 1909).

24. Blanca Muratorio, “Nación, identidad y etnicidad: imágenes de los indios ecuatorianos y sus imagineros a fines del siglo XIX". En Imágenes e imagineros: representaciones de los indígenas ecuatorianos, siglos XIX y XX, ed. por Blanca Muratorio (Quito: FLACSO Ecuador, 1994), 109-196.

25. Sobre las implicaciones de la separación entre categorías artísticas y acerca de la participación de la Escuela de Bellas Artes en la Exposición Nacional, véase Pérez, "Nace el arte moderno...".

26. Víctor Puig [Comunicación al Ministro de Instrucción Pública], Oficio n. ${ }^{\circ}$ 216, 20 de diciembre de 1909. Libro copiador de oficios de la Escuela de Bellas Artes, 1905-1913: 146-147. Quito, Archivo de la Escuela de Bellas Artes. Pástor además, presentó su libro Elementos de estética en la Sección Técnica de Bellas Letras y Ciencias en dicho pabellón, por el que mereció un diploma de honor. Catálogo General de los premios..., 21. 
la Sección Escolar de Bellas Artes, ${ }^{27}$ por primera vez un escenario externo a la EBA, y recibieron atención de la prensa, además de diplomas y medallas. ${ }^{28}$ Pástor expresó un compromiso particular con el arte joven al afirmar que "se entiende que en una exposición nacional debe tener cabida solamente todo aquello que de algún modo represente el movimiento y adelanto actual de las artes y no lo pasado que en cambio tiene alta importancia para un museo y para la historia del arte nacional" ${ }^{29}$ Su comentario apunta a algo que se insistía constantemente desde el siglo XIX y que era la necesidad de crear espacios institucionales especializados -el salón para el arte del presente, el museo para el del pasado- anhelo que se cumplió, al menos en papel, cuando en mayo de 1917 se fundaron las Galerías Nacionales de Pintura y Escultura. ${ }^{30}$

La inclusión de todo un Pabellón de Bellas Artes en la Exposición Nacional del Centenario refleja la importancia que la EBA había adquirido como gestora cultural. Estuvo ubicado en un lugar privilegiado, junto al pabellón principal, ${ }^{31}$ lo que garantizó que recibiera un gran número de visitantes. La prensa local reportó que en el primer mes de su apertura, la Exposición acogió a alrededor de 10.000 visitantes. ${ }^{32}$ Convocó no solo a los habitantes de la ciudad, sino también de provincia; recordemos que el ferrocarril había sido inaugurado en 1908. Por primera vez, la producción artística podía ser apreciada por un amplio público. ¿Quiénes podrían haber sido esos visitantes? Por fotografías de la época, vemos que la mayor parte de ellos debe haber provenido de sectores medios y altos, aunque no dejan de estar presentes campesinos y trabajadores. ${ }^{33}$ Según el Censo de la población de Quito, de 1906, los sectores medios de la ciudad lo componían abogados, comerciantes, in-

27. Ibíd., 10-13, 13-15, 17-18.

28. Los trabajos presentados por los alumnos del curso de litografía se reseñaron en "Notas: La Escuela de Bellas Artes", La Ilustración Ecuatoriana 1, n. ${ }^{\circ} 13$ (18 de septiembre de 1909): 230.

29. César Alfonso Pástor R., "Juicio artístico de la Exposición Nacional”, Revista de la Escuela de Bellas Artes III, n. ${ }^{\circ} 8$ (3 de noviembre de 1909): 146. Esta observación se dirigía a la inclusión de la Sección de Coleccionistas en la que se expuso obras del pasado.

30. Salgado y Corbalán de Celis, "La Escuela de Bellas Artes...", 57.

31. Véase el plano en María Antonieta Vásquez, El palacio de la exposición: 1909-1989 (Quito: Presidencia de la República / CCE, 1989), 41.

32. La nota "Crónica", El Comercio, 1 diciembre de 1909, dice que entre el 9 y el 30 de octubre se recaudó la suma de \$1296,30, según cita Vásquez, El palacio de la exposición..., 28, nota 4. De acuerdo al artículo 1 del Decreto Ejecutivo Reformatorio de Eloy Alfaro, las entradas estaban fijadas en 0,20 para adultos y 0,10 para niños y según el artículo 3, en días feriados, la tarifa se duplicaría. El Comercio, 10 de septiembre de 1909, citado en ibíd., 23-24. Número bastante alto si consideramos que según el censo de 1906, la ciudad tenía 50.841 habitantes. "Informe del Director General de Estadística al Ministerio del Ramo", Censo de la población de Quito, 1 ro de mayo de 1906 (Quito: s. r., 1906): 10.

33. Véanse fotografías en Vásquez, El palacio de la exposición...: 21, 25. 
dustriales y unos pocos sujetos identificados con profesiones modernas como arquitectos, fotógrafos, litógrafos y periodistas, además de pintores y escultores. La abogacía, una profesión de la cual provinieron muchos de los intelectuales de inicios del siglo, contaba con 147 profesionales en la ciudad. ${ }^{34}$ Según Bustos, estas capas medias estaban en franco crecimiento debido, en gran medida, al desarrollo del aparato estatal así como de la banca y las finanzas. ${ }^{35}$ Seguramente el sector alto, de terratenientes, también estaría presente entre los visitantes. De estos sectores de profesionales, artesanos, industriales y terratenientes provendría gran parte del público que habría visitado la gran exposición y las que se sucedieron durante la siguiente década y, sin duda, de entre los periodistas, que cuentan 16 en el censo, estarían aquellos que las comentaron. Algunos visitantes se convertirían en aficionados, que, eventualmente, practicarían una de las diversas actividades e incipientes profesiones que servirían para fortalecer el sistema artístico: periodistas culturales, críticos de arte, coleccionistas, curadores, gestores, profesores y artistas.

\section{La Exposición Anual de Bellas Artes entre 1913 Y 1916 Y LA INSTITUCIONALIZACIÓN DEL SALÓN DE ARTE}

En 1913, el Ministerio de Instrucción Pública estableció la Dirección General de Bellas Artes, cuyo objetivo fue el de fortalecer el campo cultural. Para ello se diseñó un ambicioso proyecto a través del cual se robustecerían las instituciones existentes, Conservatorio de Música, el Teatro Sucre y la EBA, la que sería transformada en "Facultad de Bellas Artes" e incorporada a la universidad. A continuación se crearía un museo nacional, una galería de bellas artes y un teatro dramático nacional. ${ }^{36}$ Como director de dicho organismo, Pedro Pablo Traversari se sitúa como uno de los principales diseñadores y ejecutores de las políticas culturales del país durante los primeros veinte años del siglo. Músico de profesión, en 1904 cuando se desempeñaba como director del Conservatorio de Música, fue encargado por el Ministerio

34. La Revista de la Sociedad Jurídico Literaria, creada en 1902, es el mejor ejemplo de esta vinculación.

35. Guillermo Bustos, "Quito en la transición: actores colectivos e identidades culturales urbanas (1920-1950)". En Enfoques y estudios históricos. Quito a través de la historia (Quito: Ilustre Municipio de Quito, 1992), 175.

36. La Dirección General de Bellas Artes fue creada por Decreto Ejecutivo el 16 de enero de 1913 como sección anexa al Ministerio de Instrucción Pública. Pedro P. Traversari, "Informe del Sr. Director General de Bellas Artes". En Luis N. Dillon, Informe Anual que Luis N. Dillon, Ministro de Instrucción Pública, Correos E Telégrafos presenta a la Nación en 1913, vol. 1 (Quito: Tipografía de la Escuela de Artes y Oficios, 1913), 743-748. 
de Instrucción Pública de restablecer la Escuela Nacional de Bellas Artes. Durante estos años, realizó su labor acompañado de otros intelectuales y artistas, José Gabriel Navarro y Sixto María Durán, quienes serían directores del EBA y el Conservatorio de Música, respectivamente, en los años 1910; los pintores Juan León Mera Iturralde y Nicolás Delgado y el escultor Luis Veloz; el hacendado, pintor aficionado y coleccionista, Pacífico Chiriboga.

La creación de la Exposición Anual de Bellas Artes fue una de las primeras acciones de dicha dirección y uno de las pocos objetivos del proyecto que llegaron a concretarse. Si se entiende el salón artístico como "aquel espacio de exhibición y discusión pública que asociamos con el mundo moderno", que se lleva a cabo regularmente y en el cual un jurado selecciona y otorga reconocimientos a los participantes, la Exposición Anual de Bellas Artes lo fue. ${ }^{37}$ Ya no estuvo circunscrita a la comunidad cercana a la EBA, sino que convocó a participantes profesionales y estuvo ubicada en un espacio público al cual accedían, sobre todo, los sectores altos, el Kiosko de la Alameda. La regularidad con la que se la convocó, sabemos que anualmente por lo menos hasta la década de 1930, y la respuesta activa de la prensa, habría permitido la formación de un público aficionado. En esos espacios de recepción, dice Kristeller, el público llega a identificarse, a compenetrarse, con lo que ve. Esa valoración es la que lleva a la consolidación de los sistemas artísticos modernos, pues los aficionados pueden, eventualmente, convertirse en promotores, en coleccionistas, en artistas. ${ }^{38}$ Algo de eso estaba ocurriendo alrededor de las exposiciones artísticas y la dinámica de recepción alrededor de ellas en el Quito de los años 1910.

¿De qué manera el modo en que estas exposiciones estuvieron concebidas, normadas y organizadas definió un ambiente de opinión y valoraciones críticas? En esta sección se examina esta normativa y la recepción de la prensa a las exposiciones con el fin de explorar como se iba configurando un sistema de valoración crítica. Durante la década de 1910, el reglamento de la exposición se publicó cada año y en él se establecían los criterios objetivos para participar, seleccionar el jurado y otorgar premios. Además se presentaba la organización de la misma en tres secciones: obras originales, sección de estudiantes de la EBA y sección de arte retrospectivo. ${ }^{39} \mathrm{Si}$ bien, como vimos

37. El salón artístico surgió en el siglo XVIII en Francia con el fin de apoyar, difundir y legitimar el rol formativo de la Academia de Bellas Artes. Véase Bruce Altshuler, Salon to Biennial-Exhibitions that made Art History, Volume 1: 1863-1859 (Londres / Nueva York: Phaidon Press, 2008).

38. Kristeller, “The Modern System...", II, 44.

39. Pedro Traversari, José Gabriel Navarro, Luis Mata et al., “Acta de sesión del Jurado de la primera Exposición Anual de Bellas Artes de Quito", Registro Oficial I, n. ${ }^{\circ} 299$ (1 de septiembre de 1913): 2989-2990. El proyecto fue presentado al Ministerio de Instrucción Pública por el director de la Escuela de Bellas Artes, José Gabriel Navarro; y el decreto 


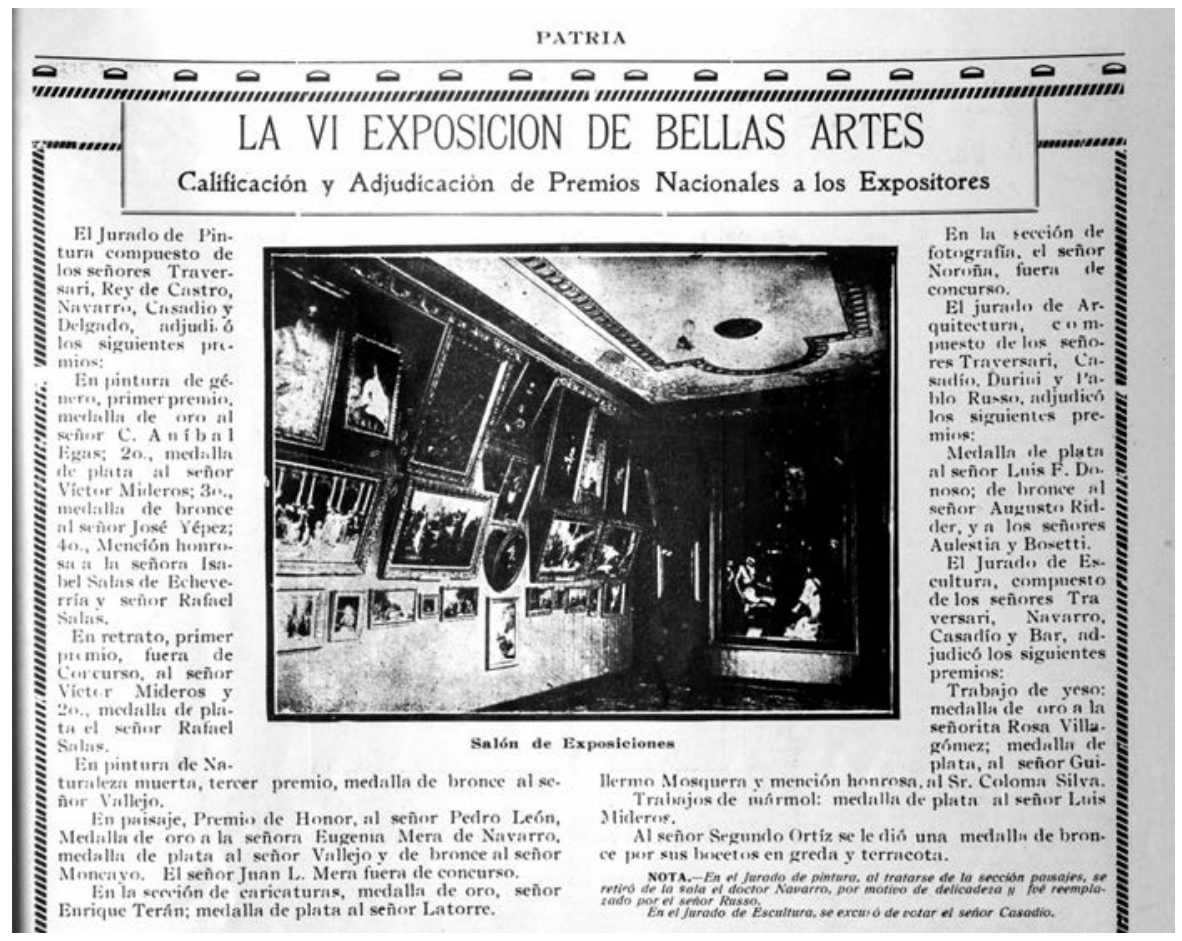

Figura 1. "La VI Exposición Anual de Bellas Artes", Patria: revista ilustrada de actualidades XIV, n. ${ }^{\circ} 150$ (1 de septiembre de 1918): 7. Fondo de Ciencias Humanas, Ministerio de Cultura, Quito. Foto: Juan Diego Pérez.

en relación a la Exposición del Centenario, la inclusión de esta última fue cuestionada, en la Exposición Anual de Bellas Artes se la mantuvo durante toda la década. Ello podría haber respondido a la legitimidad que estos coleccionistas otorgaban al evento, ya que eran individuos vinculados a la gestión política y actividad intelectual. Sin embargo, las secciones de obras originales y de estudiantes siempre tuvieron mayor espacio. Los jurados tendieron a ser personalidades vinculadas a la escena cultural y artística del momento. En la primera edición participaron Traversari, como director general de Bellas Artes; Navarro, como director de la EBA (lo era desde 1911); y Paul Bar y León Camarero, como profesores de la misma. ${ }^{40}$ Los reglamentos de la década del diez indican que la exposición estaba organizada para apoyar el arte

publicado por Leonidas Plaza, "Decreto que establece una exposición nacional de Bellas Artes", Registro Oficial I, n. ${ }^{\circ} 236$ (17 de junio de 1913): 2453-2454.

40. Traversari, Navarro, Mata et al., "Acta de sesión del Jurado...". 
del presente, tanto los artistas con cierta trayectoria como los emergentes. Es evidente que, con ello buscó delimitar y profesionalizar el campo del arte.

La prensa, por su parte, recogió las intenciones institucionales, las valoraciones del jurado, las críticas de los intelectuales y las apreciaciones del público. Los periodistas ofrecieron desde sencillas observaciones descriptivas, hasta valoraciones que examinaban críticamente las muestras y las obras. La especificidad y el carácter evaluativo de los comentarios a lo largo de los años 1910, nos hablan del desarrollo incipiente de una práctica también específica del sistema artístico moderno, el de la crítica de arte. ${ }^{41}$ A continuación se examinan esos comentarios críticos con el fin de evaluar hasta qué punto contribuyeron a configurar un sistema de valoración artística identificado con la modernidad.

El artículo 8 del reglamento de la exposición indicaba que "sólo se admitirán obras originales. Se entenderán como tales las composiciones y temas tomados del natural". ${ }^{42}$ La originalidad es un valor central a la definición moderna de arte. Sin embargo, en la incipiente escena artística quiteña de los años diez, parece que era un valor disputado, pues en uno de los primeros comentarios sobre la exposición, publicado el 13 de agosto en El Día, su autor se vio impelido a insistir en su importancia. Destaca el carácter y la innovación que imprimen a sus obras algunos de los expositores, y reprocha, en cambio, a aquellos que, como Villacrés y Cevallos, han presentado copias o trabajos exhibidos previamente en otros eventos. ${ }^{43} \mathrm{Su}$ criterio reafirma el del jurado, que condenó este proceder y excluyó del concurso a estos pintores. ${ }^{44}$ Por otra parte, si bien la originalidad era un valor abstracto que adjudicaba capital simbólico a la obra, dentro del mundo moderno era una garantía de un potencial capital material; es decir, su valor económico dependía en gran medida de su carácter innovador dentro de una tradición artística. Y así estaba reconocido en el artículo 6 del reglamento, que estipulaba las condiciones de venta de las obras expuestas. ${ }^{45}$

Es interesante notar que aunque el autor de la reseña de El Día no polemiza con el veredicto del jurado, sí profundiza en el análisis de las obras

41. Sobre la emergencia de la crítica de arte como práctica moderna, véase Shiner, $L a$ invención del arte...

42. Este artículo se repitió de forma idéntica por lo menos hasta el reglamento de la VI Exposición Anual de Bellas Artes de 1918: Pedro P. Traversari, José Gabriel Navarro, Alejandro Lemos R. et al., Reglamento de la Segunda Exposición Anual de Bellas Artes, Quito: s. r., 15 de junio de 1914; Pedro P. Traversari, José Gabriel Navarro y Jesús Vaquero Dávila, "Reglamento de la Tercera Exposición Anual de Bellas Artes", Registro Oficial IV, n. ' 830 (18 de junio de 1915): 1253-1255; y, Pedro P. Traversari, Reglamento de la VI Exposición Anual de Bellas Artes (Quito: Imprenta Nacional, 1918), 4.

43. "La Exposición de Bellas Artes del Domingo", El Día, 13 de agosto de 1913: 1.

44. Traversari, Navarro, Mata et al., "Acta de sesión del Jurado...".

45. Traversari, Navarro, Lemos R. et al., Reglamento de la Segunda Exposición... 
premiadas, utilizando un vocabulario especializado. Describe a Antonio Salguero como el expositor más destacado de la muestra, cuya obra: "se hace notable tanto por el dibujo correcto, por la expresión justa que ha sabido dar el pintor a su modelo, cuanto por ese colorido tan rico, tan caliente...". Elogia el manejo del color en las pinturas de Paul Bar, profesor de la EBA, y enfatiza el aporte que su clase de "pintura y dibujo ornamental" ha tenido en el avance de los estudiantes, quienes, en la sección estudiantil, habrían logrado exhibir "trabajos de estilización, enteramente nuevos entre nosotros". Y, sobre una pintura del alumno Víctor Mideros, que representa a una india de Zámbiza, dice que "constituye una verdadera joya artística, tanto por su dibujo como por el colorido justo y harmonioso [sic]". ${ }^{46}$

Esta larga reseña revela algunos de los parámetros que definían la función de un salón de arte: un espacio de evaluación de la producción nueva, tanto de los artistas ya establecidos como de figuras jóvenes y emergentes. La defensa de ciertos valores evidencia que ellos no estaban completamente aceptados ni por las instituciones encargadas de promover el arte ni por la sociedad que debía acogerlas. Si la copia de obras maestras europeas había sido, hasta entonces, un método pedagógico legítimo en la formación académica, el mostrarlas en un salón que buscaba identificar lo nuevo era completamente inadecuado. El lugar de esas copias podía ser el aula o una galería de reproducciones, mas no una exposición de bellas artes, en donde de lo que se trataba era, sobre todo, de medir el carácter innovador de las obras más nuevas.

En relación a la III Exposición Anual de Bellas Artes de 1915, la revista Letras publicó un largo comentario en el que Javier Andrade desplegó una serie de valoraciones que dan cuenta del grado de especialización que tanto la crítica de arte como la producción artística misma iban alcanzando. Pero, sobre todo, muestra las condiciones que permitían la estructuración de un sistema artístico moderno: la formación especializada que la EBA ofrecía como oportunidad, a través de becas al exterior, de conocer el arte europeo; las exposiciones, en cambio, permitían a los aspirantes a artistas contrastar su trabajo con el arte del pasado, con el de sus maestros y con el de sus compañeros. Todo ello había permitido, según Andrade, que los jóvenes sean parte de un "movimiento artístico del momento". ${ }^{47}$

El 10 de agosto de 1916 se inauguró la IV Exposición de Bellas Artes y la prensa le otorgó una atención excepcional. Los cronistas centraron su atención principalmente en los premios y ofrecieron al público criterios que los justificaban. Al ingresar al "salón central de la exposición, la gran escultura

46. "La Exposición de Bellas Artes del Domingo", El Día, 13 de agosto de 1913: 1.

47. Andrade, "La tercera exposición...", 249. Sobre los debates alrededor de la categoría de modernismo en el arte moderno, véase Charles Harrison, Modernismo (Londres: Encuentro / Tate Gallery, 2000). 
de Veloz nos sale al paso", decía un reportero del diario El Día en referencia a Rito eterno, obra de carácter simbolista que representa a "una ninfa a quien ha vencido la mirada de fuego y la sonrisa de irónica lascivia del fauno que la encadena con lazos de rosas y racimos de uvas", la que fue galardonada con el premio nacional, medalla de oro en escultura. Es una compleja composición en la que "se perdería otro cincel menos diestro que el del gran escultor que es ya Veloz". ${ }^{8}$ Egas, quien al igual que Veloz había vuelto de su estancia en Italia como becario de la EBA, ganó la medalla de oro con su cuadro Las floristas. Se lo identificó como un "artista entusiasta por los temas nacionales y autóctonos... [pues,] con excepción de un excelente retrato del maestro Casadio, todos los demás cuadros [...] son estudios de indias, estudios de color y de figura; y así es notable un friso compuesto de indios que llevan flores al mercado. Este cuadro tiene la adecuada caracterización de lo rítmico...". ${ }^{49}$

Algunos comentaristas resaltaban las virtudes de la formación que los jóvenes participantes habían recibido en la EBA, cuyos valores estéticos habían conseguido cristalizar en sus obras, sin dejar de cuestionar el academicismo y los convencionalismos en las producciones de ciertos alumnos. En un artículo del 15 de agosto, se comentó que "recorriendo despacio los trabajos exhibidos, vemos fácilmente que son reveladores de una enseñanza sólida, bien sistematizada... El conjunto de trabajos escolares de los alumnos de nuestra Escuela Nacional es magnífico y demuestra de manera evidente así el adelanto de ellos, como el talento y capacidad educativa del profesorado". Sobre los métodos utilizados en la enseñanza de la escultura, sigue: "estudios de anatomía y disección anatómica"; estudios tomados del natural o de otros modelos, y estudios de composición, que ayudan a que "el alumno se habitúe a la creación artística desde los primeros pasos. Y en todo esto se ve una buena dirección, de profesor inteligente, como es el señor Casadio". Resaltando la capacidad de otros maestros, dice, "nos halaga la escuela de dibujo que siguen los alumnos; la línea es recta, firme y larga, decisiva; habiendo con este método logrado los profesores, señores Víctor Mideros y Enrique Gómez Jurado, que sus alumnos presenten, como examen, dibujos maravillosos, según nos han señalado". La clase de "Composición decorativa moderna", dirigida por el profesor Bar, fue especialmente ponderada. En la primera sala estaban ubicadas "unas telas decorativas del señor León...; en la segunda, estudios y aún composiciones espléndidas, proyectos decora-

48. "La exposición de bellas artes", El Día, 12 de agosto de 1916. La escultura se encuentra en el Malecón de Guayaquil. Sobre el simbolismo en el Ecuador y América véase Alma mía. Simbolismo y modernidad...

49. "La exposición de bellas artes". 
tivos casi completos, que dan deseos de trasladarlos al sitio correspondiente de nuestra casa". 50

En 1916 otros cronistas describieron a ciertos jóvenes expositores como artistas modernos. Sobre Egas, uno de ellos dijo: "es valiente, puede ser un ingenio. Su temperamento loco, impulsivo, le conducirá a buen puesto si sigue trabajando este año, con verdadero cariño por su arte [...] Dentro de la concepción moderna del arte, ha realizado Egas el verdadero cuadro; porque el arte verdadero, hoy más que nunca, es y debe ser esencialmente decorativo". Y, continuaba que, aunque "menos fuerte en dibujo que Mideros, resulta sin embargo Egas más genial con solo este cuadro...". ${ }^{51}$ Mideros había presentado Hojas que caen, una "delicada composición, feliz de color y llena de un romanticismo", con la que mereció el premio municipal. ${ }^{52}$ En estas palabras vemos desplegados una serie de valores que nos hablan de una concepción de artista, que se mueve entre las caracterizaciones románticas del artista genio, impetuoso, audaz, voluntarioso, hasta una visión de artista capaz de acoger los valores del arte moderno como lenguaje formal autónomo.

La vinculación de las bellas artes con la construcción de la nación fue también resaltada en las observaciones de la prensa. En ocasión de la clausura de la exposición, el 24 de agosto, el comentarista de El Comercio, quien la había reseñado día a día, recogió las palabras de los organizadores del evento y de las autoridades públicas que asistieron. El acto inició con el discurso de Traversari, director general de Bellas Artes, que tuvo un tono apropiado para enmarcar el evento artístico en las metas de la nación: "La obra gigantesca que se propone el arte en favor de la humanidad, esto es, la de transportar la vida intelectual de los pueblos a la más elevada cumbre de lo bello, iluminándola con la más intensa luz de la gloria, ha tenido en el $4 .^{\circ}$ certamen artístico nacional, la mejor demostración para la patria nacional”. Luego, hizo alusión a la capacidad de las artes de fomentar el progreso y la civilización: "El adelanto de las sociedades se mide también por el florecimiento de las bellas artes, cuya misión no se restringe únicamente a la educación del espíritu en las altas concepciones de lo bello; tiene más altos horizontes y realiza una labor múltiple, civilizadora y útil, bajo todo concepto"..${ }^{53}$ Con ello

50. “La IV Exposición de Bellas Artes”, El Comercio, 15 de agosto de 1916: 1. José Gabriel Navarro definió lo que era la "pintura decorativa" en su artículo "Arte moderno", Letras 2, n. ${ }^{\circ}$ XVII (Quito, 14 de febrero de 1914): 148-151.

51. "Fiestas Patrias: La IV Exposición de Bellas Artes", El Comercio, 13 de agosto de 1916: 1 .

52. Ibíd.

53. "La clausura de la IV Exposición de Bellas Artes", El Comercio, 25 de agosto de 1916: 1. 
se buscó demostrar la función social de las artes, que debía ser reconocida por el público en general, pero sobre todo por el Estado.

Estas palabras mantienen el acento de aquellas con las que fue inaugurada la EBA una década atrás, e incluso con las de Mera veinte años antes, en las que se identificaba el arte con el progreso, la civilización y la construcción de la nación, con ello se demostraba su utilidad social y la responsabilidad que el Estado tenía en su desarrollo. ${ }^{54}$ Se enmarcaban, ahora, en una visión que permitía entender el desarrollo de las artes en el contexto de unas condiciones más favorables: ya se había establecido una academia de formación artística y una institución rectora que garantizara su permanencia y que promoviera su desarrollo. Ahora era necesario recordar al Estado su obligación moral para con este proyecto cultural, para que no descuide su apoyo económico y político. Entre los argumentos que el director de Bellas Artes esgrimió para involucrar al Estado en sus obligaciones con el arte emergente estuvo el de enmarcarlo en una tradición artística local: “los jóvenes expositores [...] son documentos irrevocables que confirman, una vez por todas, ser ellos dignos herederos del pincel quiteño que tanto renombre ha dado al país". Traversari incluye como heredera de esta tradición al arte que está surgiendo en la década del diez:

La Exposición de Bellas Artes de 1916 debe quedar en la historia nacional como época del resurgimiento del arte clásico que en preciosas telas legaron Miguel de Santiago, desde el año 1650, y los Goríbar, Samaniego, Rodríguez y Cadena hasta los Salas, Pinto y Manosalvas. Aún más, esta época significa la fundación de nuevas sendas del sentimiento personal en técnicas y géneros y estilos que se abren paso para tomar un puesto bien merecido al lado de esas glorias de la antigua pintura quiteña. ${ }^{55}$

Traversari participa, así, de un esfuerzo intelectual colectivo que se estaba llevando a cabo desde el siglo XIX y que consistía en construir una historia del arte local como un arte nacional, que se debía a una tradición, pero que también se proyectaba hacia el futuro como arte moderno. Esta lectura teleológica de la historia del arte servía para justificar el apoyo que el Estado debía continuar ofreciendo a la promoción del arte y de las instituciones que

54. Véase Rafael Orrantia, Discurso pronunciado por su autor en la velada que se celebró en el Teatro Sucre con motivo de la inauguración de la Escuela de Bellas Artes la noche del 24 de mayo de 1904 (Quito: Imprenta Nacional, 1904); Juan León Mera, “Conceptos sobre las artes" [1894]. En Teoría del arte en el Ecuador, ed. por Edmundo Ribadeneira (Quito: BCE / Corporación Editora Nacional, CEN, 1987): 291-321; José Gabriel Navarro, “El Estado y el arte", Letras 3 (Quito, octubre 1912): 88-90; Letras 5 (noviembre 1912): 142-144.

55. "La clausura de la IV Exposición...". 
se habían creado en los últimos años. ${ }^{56}$ Sus palabras, dirigidas sin duda a los representantes del poder del Estado, tuvieron un eco inmediato en el discurso que ofreció, de forma espontánea e improvisada, según el relator del diario, el presidente electo de la República, Alfredo Baquerizo Moreno, quien vio "complacido el resurgimiento del arte quiteño", y que dijo "que los artistas podían contar con el apoyo del Gobierno que ha de presidir en breve". ${ }^{57}$

La exposición de 1916 concluyó, entonces, con una apuesta por la obligación del Estado de ofrecer apoyo a las artes, la valoración del arte como elemento que promueve la civilización y el progreso y que, consecuentemente, fortalecía la construcción de la nación y del arte moderno como parte de una tradición de arte nacional. Si ya desde 1915 se identificaba el arte de los jóvenes como un movimiento artístico moderno, en 1916 se lo vería como parte de una tradición artística que enorgullece a la nación.

\section{7: LA EXPANSIÓN DEL ESPACIO EXPOSITIVO, LA CRÍTICA Y EL PÚBLICO}

1917 fue un año especialmente importante en el proceso de expansión del espacio público de las artes en Quito. Como nunca antes, se llevaron a cabo tres exposiciones entre junio y octubre: en junio, el Concurso para la Cátedra de Pintura de la EBA; en agosto, la V Exposición Anual de Bellas Artes en la que fue incluida la exposición de fin de año de los estudiantes de la EBA y la entrega, por primera vez, del Premio Mariano Aguilera; y en octubre, el Concurso para la Cátedra de Composición Decorativa Moderna de la EBA. ${ }^{58}$ Con ello se puso en evidencia no solo el dinamismo que había adquirido la escena artística de la ciudad, sino, también, la aceptación pública que habían llegado a tener los certámenes artísticos como medio de evaluación, selección, valoración y reconocimiento del arte. Se debatió quiénes debían ser, o no, los jueces idóneos en ese proceso de reconocimiento, conocedores expertos o público en general y, con ello se empezó a diferenciar el rol que cada

56. Carmen Fernández-Salvador ha explorado el modo cómo una historia del arte nacional fue construida a lo largo del siglo XIX y primera mitad del siglo XX por diversos autores, principalmente por José Gabriel Navarro. Carmen Fernández-Salvador, "Historia del arte colonial quiteño, un aporte a la historiografía". En Carmen Fernández-Salvador y Alfredo Costales Samaniego, Arte colonial quiteño: renovado enfoque y nuevos actores (Quito: Fondo de Salvamento, FONSAL, 2007), 9-122.

57. "La clausura de la IV Exposición...".

58. “Notas: concurso artístico", El Comercio, 2 de octubre de 1917: 1; “Notas: concurso de pintura", El Comercio, 4 de octubre de 1917: 1. 


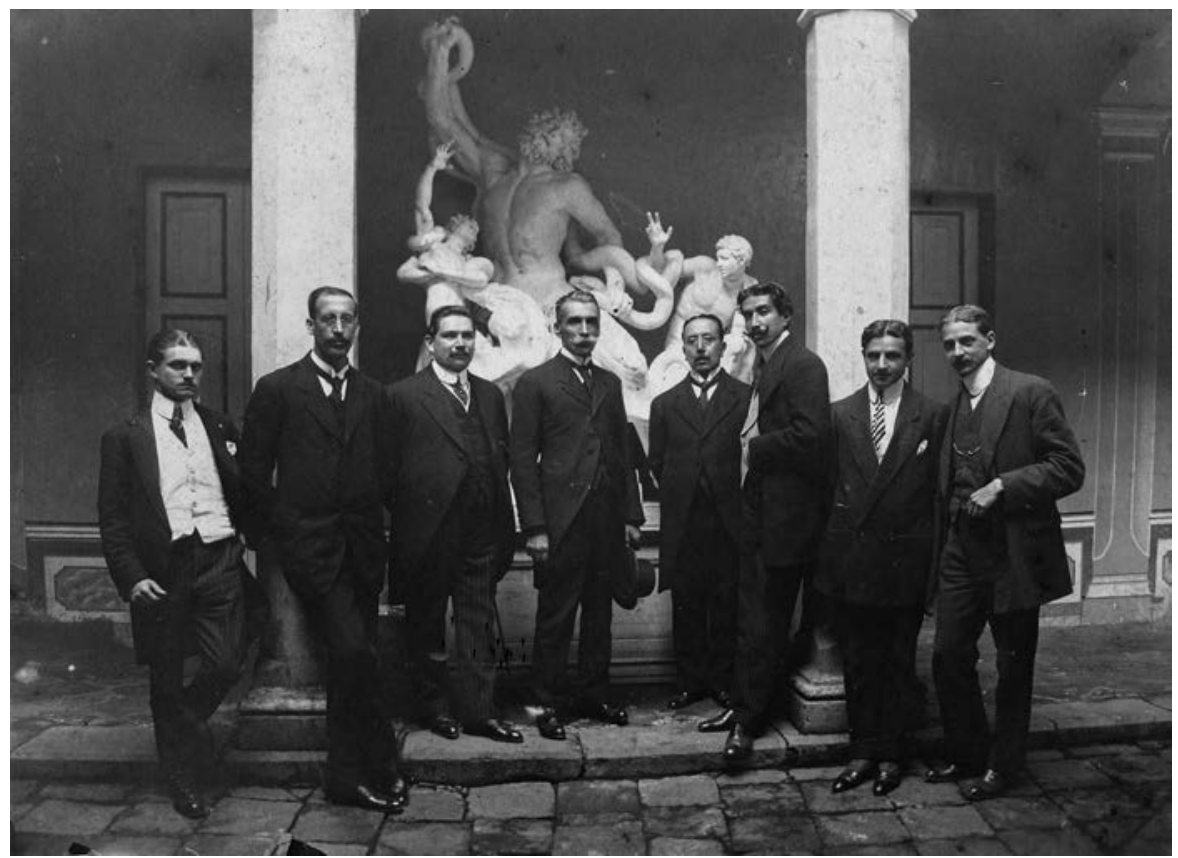

Figura 4. Fotografía anónima en la que aparecen funcionarios del gobierno de Alfredo Baquerizo Moreno (al centro) en el patio de la Escuela de Bellas Artes, con la copia en yeso del Laoconte como telón de fondo. A la izquierda del presidente se encuentran Pedro Pablo Traversari y José Gabriel Navarro. c. 1916. Fondo José Gabriel Navarro, BibliotecaArchivo Aurelio Espinosa Pólit. Reproducción fotográfica: Juan Diego Pérez.

uno de ellos cumplía en la configuración del sistema artístico. ${ }^{59}$ Revisemos a continuación algunos de los aspectos sobre los que se ocupó la prensa.

El Concurso para "la Cátedra más importante de toda EBA, como es la del Curso Superior de Dibujo y Pintura", ${ }^{60}$ se llevó a cabo en junio, ${ }^{61}$ en el Kiosko de la Alameda. ${ }^{62} \mathrm{El}$ jurado se encargó de definir el tiempo de preparación y entrega de los trabajos, el espacio de exposición y si se tomaría en cuenta, o

59. Esta preocupación por la formación de conocimientos expertos manifiesta un proceso de modernización cultural. Véase Anthony Giddens, Consecuencias de la modernidad (Madrid: Alianza Editorial, 1999).

60. Pedro P. Traversari, Rafael Pino y Roca, José Gabriel Navarro et al., "El concurso de pintura: informe del jurado", El Comercio, 26 de junio de 1917: 1.

61. César Alfonso Pástor, "La clase de pintura", El Día, 30 de mayo de 1917: 2; "Informaciones: Concurso de pintura", El Comercio, 31 de mayo de 1917: 1.

62. "Sobre el concurso de pintura", El Día, 2 de junio de 1917: 4. 
no, el voto del público. ${ }^{63}$ Tres fueron los aspirantes: Camilo Egas, Víctor Mideros y José Abraham Moscoso. El certamen fue inusual en varios aspectos. Según un periodista habría sido "el primer caso que durante nuestra vida republicana, la provisión de una cátedra va a discernirse consultando las aptitudes, buscando el hombre para el empleo y no el empleo para el hombre". ${ }^{64}$ Estamos frente al reconocimiento del certamen como una práctica moderna en la que la selección se hace a partir de criterios previamente racionalizados.

De forma inédita, también, se decidió que los visitantes emitieran su juicio. A pesar de que con ello se garantizó una concurrencia masiva del públi$\mathrm{co}$, no todos estuvieron de acuerdo en que este pudiera ser juez competente en asuntos sobre los que no tenían experticia. ${ }^{65}$ Por un lado, se trataba de formar un público que aprendiera a apreciar el arte, pero por otro, se buscaba que este fuera informado y calificado. Un comentarista, que firmaba como Anacarsis, muestra una posición ambivalente frente a ello. En un momento, se preguntó: “QQué dice el vulgo?, cuál es la obra que le atrae o impresiona [...]. Tomo un ángulo del salón y en él me planto a ver circular la gente, y a escuchar los diversos gustos y pareceres de ese gran jurado que de hecho constituyen las muchedumbres". ${ }^{66}$

Se trata de un público cuyas apreciaciones son espontáneas, aunque ingenuas, que se "agolpa" ante las obras. Está compuesto por "dilettanti que aman el arte sin penetrarlo y sobre todo las señoritas..., [para quienes]... todo aquello en que juega su papel el amor les atrae... ¿Qué cosa más tierna, más dulce y más sugestiva para ellos?" que el tema que se representa en $E l$ festín de Mideros. El tono condescendiente de su juicio, especialmente hacia las mujeres y los indígenas, está ligado a la noción imperante de bellas artes y su anclaje en jerarquías de clase y género. ${ }^{67}$ En contraste, encuentra que

63. Sus miembros fueron un representante del Ministerio de Instrucción Pública, el señor Rafael Pino y Roca, el director de Bellas Artes, Traversari; el director de la Escuela de Bellas Artes, Navarro; y tres profesores de la misma: Luis Casadio, Paul Bar y Juan León Mera Iturralde. Traversari, Pino y Roca, Navarro et al., "El concurso de pintura: informe...".

64. "Notas: Concurso de pintura", El Comercio, 23 de junio de 1917: 1.

65. "En la Alameda", El Día, 4 de junio de 1917: 4; F. Guarderas, "El concurso para proveer a la Cátedra de pintura de la Escuela de Bellas Artes", Revista de la Sociedad JurídicaLiteraria XVIII, n. ${ }^{\circ}$ 47-48 (abril-marzo 1918): 274.

66. Anacarsis, "En el Kiosko de La Alameda", El Día, 10 de junio del 1917: 2. Anacarsis era el seudónimo de Francisco P. de Soria, según Carlos A. Rolando, Cronología del periodismo ecuatoriano. Pseudónimos de la prensa nacional (Guayaquil: Imprenta y papelería mercantil Monteverde \& Velarde, 1920), 153.

67. Para una discusión sobre las bellas artes como signo de diferenciación social en el contexto específico de la ciudad de Quito a inicios del siglo XX, véase Salgado y Corbalán de Celis, "La Escuela de Bellas Artes...". 
la obra presentada por Moscoso convoca a un público más especializado: "entre ellos he tenido la paciencia de contar cinco personas de reconocida cultura, un abogado y unos cuantos alumnos de la Escuela de Bellas Artes". Nuevamente, sin abandonar sus prejuicios de género, recoge las observaciones de los entendidos: el abogado dice, "¡me hace pensar!", el filósofo "aquí hay un alma", una mujer: "iqué cuadro tan seco!”. Al terminar su recorrido, Anacarsis concluye con una valoración que contradice su primera percepción: "salgo [...] obsesionado de la divergibilidad del criterio popular, de su inconsistencia y de su evidente peligro" ${ }^{68}$

El problema no era solamente el público. En realidad, el local escogido para montar la exposición era claramente inadecuado. El Kiosko de la Alameda, que era el lugar en donde se había montado la exposición desde 1913, era un espacio demasiado pequeño, en donde los visitantes no podían tener la distancia física y la tranquilidad espiritual para poder apreciar adecuadamente las obras expuestas. Al aproximarse a la exposición Anacarsis observó "que esta tiene lugar en un saloncillo lateral, escaso para contener veinte visitantes; estos que no son pocos y en continuo vaivén [...] hasta se pisan mutuamente, al pretender tomar, para apreciar cada cuadro, la distancia conveniente" ${ }^{\prime 6}{ }^{6}$ Este comentario dirige nuestra atención hacia uno de los valores centrales de la definición moderna de arte, el de la contemplación pura, la misma que solo podía ocurrir en un espacio expositivo que evitara las interferencias externas. Es de este requerimiento que nacieron instituciones artísticas modernas como la sala de exposición, la galería o el museo. ${ }^{70} \mathrm{Y}$ explica la insistencia de los agentes culturales de entonces a favor de su creación.

Al discernir las cualidades que garantizarían una carrera artística futura, el jurado valoró la habilidad en la representación naturalística, expresada en la corrección del dibujo y la composición; la capacidad del pintor de producir obras originales; y el ímpetu expresivo que habría sido capaz de encarnar en su obra. ${ }^{71}$ El jurado escogió a Camilo Egas, a pesar de que se consideró que su pintura presentaba defectos de ejecución, pues, de todos modos, "imprime nuevo y positivo rumbo al arte ecuatoriano: considerada como una de las obras iniciales en la carrera de un artista, es genial". ${ }^{72}$

68. Anacarsis, “En el Kiosko...", 2.

69. Ibíd.

70. Para una discusión sobre el concepto de contemplación pura en el arte moderno, véase Brian O'Doherty, Inside the White Cube: The Ideology of the Gallery Space, ed. ampliada (Berkeley / Londres: University of California Press, 1999).

71. "El concurso de pintura", El Día, 8 de junio de 1917: 1. Como criterio para escoger el mejor profesor, se evaluó la presentación de un programa pedagógico. Traversari, Pino y Roca, Navarro et al., "El concurso de pintura: informe...".

72. Ibíd. 
Se reclamaba que se pronunciaran los 'críticos profesionales', que debían ser capaces de analizar "las condiciones fundamentales de colorido, dibujo, etc., de los cuadros". ${ }^{73}$ Los miembros del jurado como algunos comentaristas eran, sin duda, versados en el análisis de los valores de una obra artística y manejaban un lenguaje especializado. La experticia de Navarro, Casadio y Bar se sustentaba en sus prácticas, como profesor de estética, el primero, como artistas y docentes de escultura y pintura, los segundos. Así, su análisis demostraba esas competencias. Con respecto al trabajo de Mideros, el jurado dijo que "como composición es académico, aún se puede decir que no la hay en el sentido artístico de la palabra; pues sus figuras que parecen recortadas, se encuentran sólo yuxtapuestas". Su cuadro "está pintado... con demasiada facilidad y cálculo y con falta de observación". En El sanjuanito de Egas se estimó "el carácter general de la composición"; sin embargo, se consideró que

desagrada [...] el paralelismo entre las líneas de los brazos y las de las piernas del indio que baila, [...] que, unido a la verticalidad de los pliegues del poncho y al demasiado cuidado en los detalles, tanto de forma como de color, suspende el movimiento de la figura. Los indios del señor Egas aparecen en pose, para ser copiados. $^{74}$

"El criollismo de Egas", un artículo dedicado principalmente a elogiar la obra ganadora, resaltó el modo cómo ella imprime una renovación plástica en la representación de las sociedades indígenas. ${ }^{75}$ Entonces, el veredicto del jurado permite apreciar el ejercicio crítico involucrado en la tarea.

La V Exposición Anual de Bellas Artes introdujo dos innovaciones. La primera, un cambio en la normativa que permitía por primera vez que los expositores nombrasen a uno de los jurados: en este caso el escultor Luis F. Veloz. ${ }^{76}$ La segunda fue más importante: la inclusión del premio Mariano Aguilera. El benefactor Mariano Aguilera había muerto en 1916 dejando un legado que debía servir para solventar los premios de la Exposición Anual de Bellas Artes. ${ }^{77} \mathrm{Su}$ herencia consistía en una casa de valor aproximado de

73. "El concurso de pintura".

74. Traversari, Pino y Roca, Navarro et al., "El concurso de pintura: informe...".

75. "El criollismo de Egas" [fuente de prensa no identificada] c. 1917. Archivo de Camilo y Claire Egas, en custodia de Trinidad Pérez. Para una discusión más amplia sobre esta obra y su recepción crítica, véase mi artículo "Raza y modernidad en Las floristas y El sanjuanito de Camilo Egas". En Estudios ecuatorianos: un aporte a la discusión, comp. por Ximena Sosa-Buchholz (Quito: FLACSO Ecuador / Abya-Yala, 2006), 155-165.

76. "Informaciones: Concurso de Bellas Artes", El Comercio, 7 de agosto de 1917: 4; "Jurado de Bellas Artes", El Comercio, 8 de agosto de 1917: 4.

77. “Informaciones: Premio Mariano Aguilera", El Comercio, 9 de junio de 1917: 4. 
\$30.000 que sería manejada por el Municipio de la capital. De “lo que produzca anualmente, los intereses e intereses de intereses, será dedicado para los expositores de bellas artes que se hace cada 10 de agosto" ${ }^{78}$ Traversari fue encargado por el presidente del Concejo Municipal de Quito de preparar un proyecto de concursos que recoja la herencia del benefactor. Lo incorporó a la Exposición Anual a través de dos mecanismos: la participación de un jurado nombrado por el Concejo Municipal ${ }^{79}$ y la distribución de la herencia en premios: "la cantidad de seiscientos cincuenta y tres sucres ochenta y dos centavos a que asciende el producto del legado se dividirá en seis partes, de las cuales, tres corresponden al primero de pintura, las dos al de escultura, y la última, al de arquitectura" ${ }^{80}$ El premio de pintura lo recibió Víctor Mideros, el de escultura Luis Mideros y el de arquitectura, Luis Aulestia. ${ }^{81}$ Las diferencias en la cantidad de dinero que fue otorgada a cada una de estas secciones, ratificaron las jerarquías que el sistema de las bellas artes establecía, con la pintura a la cabeza.

Cuando en octubre se llevó a cabo un segundo concurso por una cátedra de la EBA, el de pintura decorativa, para el que fue ratificado el profesor Bar, culminó la actividad expositiva del año. Un año en el que, gracias a ello, la escena artística se dinamizó notablemente. Si bien la especialización en las valoraciones críticas se acrecentaba, ellas tendían al consenso, posiblemente porque los esfuerzos se centraban en la consolidación de los espacios de institucionalización del arte.

\section{El fin de los acuerdos: el Mariano Aguilera,}

\section{LA MANZANA DE LA DISCORDIA}

Al inaugurarse la VI Exposición Anual de Bellas Artes en agosto de 1918, la organización del sistema artístico parecía bastante avanzado. Se había alcanzado un equilibrio entre lo normativo y la autonomía del campo artístico, pues los artistas habían logrado tener más control sobre el devenir de su ámbito de acción al participar en la selección del jurado y no solo ser expositores; todo ello, claro, sin que los funcionarios dejaran de mantener el control. Traversari continuaba siendo el director general de Bellas Artes, pero su círculo de colaboradores se había ampliado: junto a Navarro se in-

78. "Estímulo artístico", El Día, 6 de mayo de 1916.

79. "Exposición de Bellas Artes", El Día, 18 de agosto de 1917: 4. Véase también "Fiestas patrias: Exposición de Bellas Artes", El Comercio, 11 de agosto de 1917: 4.

80. "Hechos diversos: El Premio Aguilera", El Día, 22 de agosto de 1917: 4.

81. "Informaciones: Los tres premios", El Comercio, 30 de agosto de 1917: 4; "Hechos diversos: El Premio 'Aguilera'". 
corporaron algunos graduados de la EBA que habían gozado de becas en Europa, como Luis Veloz y Nicolás Delgado, quien actuaba como secretario de la exposición. El Kiosko de la Alameda pertenecía ahora al sistema de Museo y Galerías Nacionales. ${ }^{82}$ Nos encontramos, entonces, en un momento descollante en la formación del sistema artístico moderno, en el cual el elemento de reconocimiento social estuvo también presente.

El discurso presentado en la inauguración por parte de Traversari buscó resaltar, precisamente, el papel de las exposiciones como "el mejor de los estímulos morales". Hizo notar que las exposiciones anuales habrían llevado al mismo filántropo Mariano Aguilera a dejar su legado para garantizar "la vida de dicha exposición, que es la vida misma del artista". Así mismo, subrayó la importancia de que el Municipio de Quito, administrador del premio, haya sabido interpretar los deseos del benefactor al permitir un "acuerdo para que esta exposición mientras subsista, sea la misma en la que se confiera el premio Aguilera, como fue la verdadera intención de su creador" ${ }^{83}$ Es decir, en su alocución Traversari insistió en que el Mariano Aguilera sea un "premio" que se entregue en las exposiciones anuales, y no un certamen aparte.

No obstante, el optimismo que Traversari expresó en el discurso inaugural pronto fue opacado por una serie de controversias. Algunos pensaron que el reglamento debía ser más laxo y admitir obras tardíamente; otros lo defendieron aludiendo al nivel de formalidad que había alcanzado el concurso, precisamente gracias a él. ${ }^{84} \mathrm{Si}$ debía existir o no una comisión de preselección o solo un jurado de premiación fue otro tema en disputa. ${ }^{85}$ Como en años anteriores, se seguía comentando lo inadecuado del espacio expositivo y se empezó a hablar de la posibilidad de la construcción de un Palacio de Bellas Artes. ${ }^{86}$

El principal punto de controversia fue, sin embargo, el Premio Mariano Aguilera. Algunos consideraron que el reconocimiento económico había sido la 'manzana de la discordia' ${ }^{87}$ Por otra parte, mientras que la Exposición Anual se regía a partir de un reglamento bien elaborado, el Premio

82. Traversari, Reglamento de la VI Exposición...

83. Pedro P. Traversari y Manuel E. Escudero, “VI Exposición de Bellas Artes: Discurso del Sr. Dn. Pedro P. Traversari, Director General de Bellas Artes, en el acto inaugural de la Exposición; Discurso del Sr. Dn. Manuel E. Escudero, Ministro de Instrucción Pública", El Comercio, 12 de agosto de 1918: 1.

84. Sobre esta particular discusión, véase: XX, "La Exposición de Bellas Artes", El Comercio, 15 de agosto de 1918: 1; Negri, "Reparos a un aficionado de arte", El Comercio, 17 de agosto de 1918: 4.

85. XX, "La Exposición de Bellas Artes".

86. Ibíd.

87. Pancho Lista, "La VI Exposición de Bellas Artes", El Comercio, 17 de agosto de 1918: 1. Pancho Lista era el seudónimo de Alejandro Campaña según Rolando, Cronología del periodismo..., 102. 
Mariano no tenía uno. En agosto, Pancho Lista llegó a proponer que, en esta edición, el Premio fuera declarado desierto, en vista de que habían pocos expositores (apenas catorce o quince) ${ }^{88} \mathrm{y}$, sobre todo, porque corría la voz de que los jurados "se han puesto en juego por los interesados". ${ }^{89}$ Además de que aparecía "todo desprovisto de un mediano gusto estético", lienzos de colores chillones, figuras desproporcionadas, además de copias de estampas y fotografías. ${ }^{90}$ Para sumar al desconcierto, para decepción de todos y como muestra de las tensiones que vivió esta edición de la Exposición Anual de Bellas Artes, no se entregaron las medallas correspondientes y se denunció que no se lo hacía desde 1916.91

En medio de la confusión, el Concejo Municipal de Quito, administrador del Premio Mariano Aguilera, decidió trasladarlo a octubre y convertirlo en un certamen independiente..$^{2}$ Ello redundó en una organización apresurada, que despertó una nueva polémica: se mencionó la falta de experiencia del Concejo Municipal en asuntos de arte; se reclamó que su convocatoria no haya atendido a ninguno de los criterios que a lo largo de los años se habían consolidado en la Exposición Anual de Bellas Artes. ${ }^{93}$ La exposición del Premio Mariano Aguilera fue considerada un fracaso. ${ }^{94}$

¿Qué señalan las controversias suscitadas alrededor de la VI Exposición Anual de Bellas Artes y el Premio Mariano Aguilera en 1918? Es evidente que este último tensionó las formas de circulación y legitimación que se habían establecido desde 1913. Si por un lado la Exposición Anual se había posicionado en la escena artística desde los esfuerzos de un sector de profesionales del arte y la cultura, el Concejo Municipal parecía disputar esa hegemonía, y lo hacía desde la improvisación y el amateurismo. Un indicio adicional de que se estaba anticipando un cambio en la escena artística local es la aparición a fin de año de la revista Caricatura. Manejada por una comunidad de artistas jóvenes salidos de las aulas de la EBA, el énfasis de la revista en la caricatura implicó un distanciamiento del estatuto de las

88. Ibíd., “La VI Exposición de Bellas Artes”, El Comercio, 14 de agosto de 1918: 1.

89. Ibíd., 17 de agosto de 1918: 1.

90. Ibíd., "El certamen de arte", El Comercio, 13 de octubre de 1918: 4.

91. "La clausura de la Exposición Nacional", El Comercio, 22 de agosto de 1918: 4.

92. "Por las artes y los artistas", El Día, 26 de septiembre de 1918: 2. La muestra fue inaugurada el 9 de octubre, según la información de "Aviso: Exposición de Bellas Artes", El Día, 3 de octubre de 1918: 3; "El premio Aguilera: Exposición de pintura (de El Día, 10 de octubre de 1918)", Boletín de la Biblioteca Nacional 1, n. 4 (octubre 1918): 184-185. La Exposición Anual de Bellas Artes desapareció algunos años después; pero el Salón Mariano Aguilera sigue llevándose a cabo, aunque su formato fue actualizado últimamente para responder a las necesidades del arte contemporáneo y hoy se denomina "Nuevo Mariano".

93. “Exposición Aguilera", El Día, 13 de octubre de 1918: 2.

94. Ibíd. 
bellas artes, que privilegiaba la pintura y la escultura y, por tanto, de los métodos de la academia que los había formado. Desde una posición crítica y radical frente al mundo artístico y social de Quito, el semanario cuestiona la hegemonía de quienes hasta entonces habían dominado la gestión cultural en la ciudad, Traversari y Navarro. Esa posición reflexiva permitió que articularan un nuevo espacio independiente y autónomo de las instancias oficiales. ${ }^{95}$

\section{CONClusiones}

Los acontecimientos de 1918 marcan el fin de un momento inicial de formación de un sistema artístico en el que se establecen espacios institucionales, se inicia un ámbito de deliberación y se empieza a formar un público interesado en el arte. En 1918 ese sistema se reconfigura como un espacio en el que, además, se disputan posiciones; es decir, como un campo, en el sentido de Bourdieu. ${ }^{96}$ En este artículo se ha discutido cómo la creación de instituciones como la EBA y la Dirección General de Bellas Artes permitieron estructurar ese sistema en el Quito de inicios del siglo XX. Aparecen como los ejes desde los cuales fue posible proyectar la actividad artística al espacio público y, con ello, propiciar un interés en visitantes y espectadores, hasta convertirlos en críticos de arte, coleccionistas o, sencillamente, en aficionados que podían compartir su simpatía por el arte.

Se ha visto que se trata de un sistema artístico configurado por una serie de elementos identificados con la modernidad. Las instituciones que organizan de forma estructurada y ordenada; los gestores lo hacen desde posiciones de profesionalismo, los artistas se forman sistemáticamente, la prensa actúa como propagadora de ideas. En su articulación, estos elementos contribuyeron a crear un ambiente de apreciación del arte en su estatuto moderno. También acorde a los valores de la modernidad, fueron responsables del florecimiento de posiciones críticas a su naturaleza oficial y reglamentaria.

$\mathrm{El}$ arte que se produjo fue parte de estas interacciones y es en ellas que se definió. Es decir, aquello que Egas, Mideros o cualquiera de los otros jóvenes presentaron en las exposiciones artísticas fue posible por las condi-

95. Sobre el carácter crítico de la caricatura en esta y otras revistas véase María Elena Bedoya, Los espacios perturbadores del humor: revistas, arte y caricatura 1918-1930 (Quito: BCE, 2007); Yesenia Villacrés, "Revista Caricatura: renovación del campo cultural quiteño por un grupo de 'intelectuales de talento', 1918-1924" (tesis de licenciatura, Pontificia Universidad Católica del Ecuador, PUCE, 2007).

96. Pierre Bourdieu, Las reglas del arte, génesis y estructura del campo literario (Barcelona: Anagrama, 2005). 
ciones de formación, de circulación de ideas y de obras artísticas, de apreciación y legitimación que se crearon. En medio de ello, entonces, se puede hablar de que estos jóvenes eran o no artistas, eran o no modernos y si las instituciones y los modos de valoración se ajustaban o no a los valores de la modernidad.

Centrar la investigación en la configuración de un sistema artístico en lugar de solo en la producción o trayectoria de los autores permite entender el arte en sus condiciones sociales de posibilidad, desde las más inmediatas, como el sistema de valores o las instituciones, hasta las más amplias, como las condiciones históricas de un tiempo y un lugar. En este estudio, se han observado unos acontecimientos ocurridos en un momento corto en un lugar específico, y con ello se ha querido explorar las condiciones particulares que los hicieron posible. Una de las conclusiones ha sido que esta estructuración inicial del sistema artístico permitió futuros desarrollos. Pero, también, que no podemos tomar esa estructuración como algo permanente o fijo; sino, más bien, como momentos que una vez que ingresan nuevas condiciones, pueden cambiar y reconfigurarse. En eso nos puede, nuevamente, resultar útil recurrir al concepto de campos de Bourdieu, para quien su articulación depende de la acción, siempre en disputa, de unos actores, siempre cambiantes. Pero, de todas maneras, parece ser cierto que la estructuración inicial de un sistema artístico moderno en Quito, permitió el desarrollo, en las siguientes décadas, de un campo artístico moderno en la ciudad.

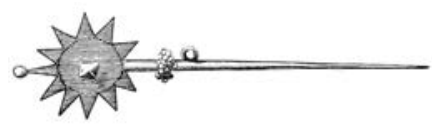

\section{FUENTES Y BIBLIOGRAFÍA}

\section{ARCHIVOS}

Archivo-Biblioteca Aurelio Espinosa Pólit, Quito (BAEP).

Archivo de la Escuela de Bellas Artes, Facultad de Artes, Universidad Central del Ecuador, Quito.

Archivo Histórico y Biblioteca del Ministerio de Cultura del Ecuador, Quito.

Archivo Nacional de Historia, Quito (ANE).

Biblioteca Nacional del Ecuador Eugenio Espejo, Quito.

Hemeroteca del diario El Comercio, Quito. 


\section{FUENTES PRIMARIAS PUBLICADAS}

Anacarsis. "En el Kiosko de La Alameda”. El Día. 10 de junio del 1917: 2.

Andrade, Javier. "La tercera exposición nacional de Bellas Artes de Quito". Letras IV, n. ${ }^{\circ} 32$ (septiembre 1915): 248-250.

. "La tercera exposición nacional de Bellas Artes de Quito". Letras IV, n. 33 (octubre 1915): 265-266.

Catálogo General de los Premios Conferidos por el Jurado de la Exposición a los concurrentes al Certamen Nacional, inaugurado en la capital de la República del Ecuador el 10 de agosto de 1909 con motivo del Centenario de la Independencia Sud-Americana. Quito: Imprenta y Encuadernaciones Nacionales, 1910.

Constitución de la República del Ecuador, 1835.

["Decreto del Poder Ejecutivo"], Registro Oficial II, n. 518 (11 de noviembre de 1907): 1983-1987.

"El criollismo de Egas" [fuente de prensa no identificada] c. 1917. Archivo de Camilo y Claire Egas, en custodia de Trinidad Pérez.

"El premio Aguilera: Exposición de pintura" (El Día, 10 de octubre de 1918)". Boletín de la Biblioteca Nacional 1, n. ${ }^{\circ} 4$ (octubre 1918): 184-185.

Espejo, Eugenio. Primicias de la Cultura de Quito, n. 6 (15 de marzo de 1792).

Guarderas, F. “El concurso para proveer a la Cátedra de pintura de la Escuela de Bellas Artes". Revista de la Sociedad Jurídico-Literaria XVIII, n. ${ }^{\circ}$ 47-48 (abril-marzo 1918): 274.

"Informe del Director General de Estadística al Ministerio del Ramo". En Censo de la población de Quito, 1 ro de mayo de 1906, Quito: s. r., 1906: 10.

La Escuela de Pintura de Cuenca: su primera exposición de dibujo, julio 30 de 1893. Cuenca: Universidad del Azuay, 1893.

Larrea, Jenaro. Reglamento Oficial para la Exposición Nacional. Quito: Imprenta Nacional, 1909.

Navarro, José Gabriel. "Arte moderno". Letras, n. ${ }^{\circ}$ XVII, año 2. Quito, 14 de febrero de 1914: 148-151.

“El Estado y el arte". Letras, n. ${ }^{\circ}$ 3, año 1. Quito, octubre 1912: 88-90.

"El Estado y el arte". Letras, n. ${ }^{\circ}$ 5, año 1. Quito, noviembre 1912: 142-144.

Negri. "Reparos a un aficionado de arte". El Comercio. 17 de agosto de 1918: 4.

"Notas: La Escuela de Bellas Artes". La Ilustración Ecuatoriana 1, n. ${ }^{\circ} 13$ (18 de septiembre de 1909): 9.

Orrantia, Rafael. Discurso pronunciado por su autor en la velada que se celebró en el Teatro Sucre con motivo de la inauguración de la Escuela de Bellas Artes la noche del 24 de mayo de 1904. Quito: Imprenta Nacional, 1904.

Pancho Lista. "El certamen de arte". El Comercio. 13 de octubre de 1918: 4. "La VI Exposición de Bellas Artes". El Comercio. 14 de agosto de 1918: 1. "La VI Exposición de Bellas Artes". El Comercio. 17 de agosto de 1918: 1.

Pástor, César Alfonso. "Juicio artístico de la Exposición Nacional". Revista de la Escuela de Bellas Artes III, n. ${ }^{\circ} 8$ (noviembre 3 de 1909): 145-147.

"La clase de pintura". El Día. 30 de mayo de 1917: 2. 
Plaza, Leonidas. "Decreto que establece una exposición nacional de Bellas Artes". Registro Oficial I, n. 236 (17 de junio de 1913): 2453-2454.

Puig, Víctor. [Comunicación al Ministro de Instrucción Pública], Oficio n. ${ }^{\circ}$ 216, 20 de diciembre de 1909. Libro copiador de oficios de la Escuela de Bellas Artes, 1905-1913: 146-147. Quito, Archivo de la Escuela de Bellas Artes.

[Puig, Víctor]. “Discurso del Director de la Escuela con motivo de la repartición de premios y exposición escolar celebrada el día $1^{\circ}$ de noviembre de 1909". Revista de la Escuela de Bellas Artes III, n. ${ }^{\circ} 8$ (3 de noviembre de 1909): 143-144.

Traversari, Pedro P. "Informe del Sr. Director General de Bellas Artes". En Luis N. Dillon, Informe Anual que Luis N. Dillon, Ministro de Instrucción Pública, Correos E Telégrafos presenta a la Nación en 1913. Vol. 1, 743-748. Quito: Tipografía de la Escuela de Artes y Oficios, 1913.

. Reglamento de la VI Exposición Anual de Bellas Artes. Quito: Imprenta Nacional, 1918.

José Gabriel Navarro, Alejandro Lemos R., Jesús Vaquero Dávila, Sánchez, Moreno. Reglamento de la Segunda Exposición Anual de Bellas Artes. Quito: s.p.i, 15 de junio de 1914.

José Gabriel Navarro, Luis Mata, Antonio Salguero, L. Camarero, A. Bar, Federico Páez, Juan León Mera, Jesús Baquero Dávila. "Acta de sesión del Jurado de la primera Exposición Anual de Bellas Artes de Quito". Registro Oficial I, n. 299 (1 de septiembre de 1913): 2989-2990.

José Gabriel Navarro y Jesús Vaquero Dávila. “Reglamento de la Tercera Exposición Anual de Bellas Artes", Registro Oficial IV, n. 830 (18 de junio de 1915): 1253-1255.

Rafael Pino y Roca, José Gabriel Navarro, Luigi Casadio, A. Bar y Juan León Mera Iturralde. "El concurso de pintura: informe del jurado". El Comercio, 26 de junio de 1917: 1.

y Manuel E. Escudero. “VI Exposición de Bellas Artes: Discurso del Sr. Dn. Pedro P. Traversari, Director General de Bellas Artes, en el acto inaugural de la Exposición; Discurso del Sr. Dn. Manuel E. Escudero, Ministro de Instrucción Pública". El Comercio, 12 de agosto de 1918: 1.

Sociedades Democráticas de Ilustración, de Miguel de Santiago y Filarmónica: Discursos pronunciados en la sesión pública de exhibición efectuada el 6 de marzo de 1852 por los miembros de las Sociedades Democráticas de Ilustración, de Miguel de Santiago y Filarmónica, en el séptimo aniversario del seis de marzo de 1845 [1. ${ }^{a}$ ed. Quito: Imprenta F. Bermeo, 1852]. Copia facsimilar, Colección Fuentes y Documentos para la Historia de la Música en el Ecuador II. Quito: Banco Central del Ecuador (BCE), 1984.

XX. "La Exposición de Bellas Artes". El Comercio. 15 de agosto de 1918: 1.

\section{Periódicos}

El Comercio. Quito, 1916-1918.

El Día. Quito, 1916-1918. 


\section{FUENTES SECUNDARIAS}

Acuña, Ruth. Alberto Urdaneta: coleccionista y artista. Bogotá: Universidad Nacional de Colombia, 2010.

“El Papel Periódico Ilustrado y la génesis de la configuración del campo artístico en Colombia". Tesis de maestría. Universidad Nacional de Colombia, sede Bogotá. 2002.

Altshuler, Bruce. Salon to Biennial-Exhibitions that made Art History, Volume I: 18631959. Londres / Nueva York: Phaidon Press, 2008.

Bedoya, María Elena. Los espacios perturbadores del humor: revistas, arte y caricatura 1918-1930. Quito: BCE, 2007.

Borja González, Galaxis. "'Sois libres, sois iguales, sois hermanos'. Sociedades democráticas en Quito de mediados del siglo XIX". JahrbuchfürGeschichteLateinamerikas / Anuario de Historia de América Latina 53 (2016): 185-210.

Bourdieu, Pierre. Las reglas del arte, génesis y estructura del campo literario. Barcelona: Anagrama, 2005.

Bustos, Guillermo. “Quito en la transición: actores colectivos e identidades culturales urbanas (1920-1950)". En Enfoques y estudios históricos. Quito a través de la historia, 163-188. Quito: Ilustre Municipio de Quito, 1992.

Cevallos, Pamela. La intransigencia de los objetos: la Galería Siglo XX y la Fundación Hallo en el campo del arte moderno ecuatoriano [1964-1979]. Quito: Fundación Museos de la Ciudad / Centro de Arte Contemporáneo, 2013.

Chartier, Roger. Espacio público, crítica y desacralización en el siglo XVIII. Los orígenes culturales de la Revolución francesa. Barcelona: Gedisa, 1995.

De la Maza Chevesich, Josefina. "Por un arte nacional: pintura y esfera pública en el siglo XIX chileno". En Ciencia-mundo: orden republicano, arte y nación en América, 279-318. Santiago: Editorial Universitaria, 2010.

Fernández-Salvador, Carmen. "Historia del arte colonial quiteño, un aporte a la historiografía". En Carmen Fernández-Salvador y Alfredo Costales Samaniego, Arte colonial quiteño: renovado enfoque y nuevos actores, 9-122. Quito: FONSAL, 2007.

Giddens, Anthony. Consecuencias de la modernidad. Madrid: Alianza Editorial, 1999.

Harrison, Charles. Modernismo. Londres: Encuentro / Tate Gallery, 2000.

Hartup, Cheryl Diane. "Artists and the New Nation: Academic Painting in Quito During the Presidency of Gabriel García Moreno (1861-1875)". Tesis de maestría. University of Texas at Austin. 1997.

Kennedy Troya, Alexandra. "Del taller a la Academia: educación artística en el siglo XIX en Ecuador". Procesos: revista ecuatoriana de historia, $n .{ }^{\circ} 2$ (I semestre de 1992): 119-134.

y Rodrigo Gutiérrez Viñuales, editores y coordinadores. Alma mía. Simbolismo y modernidad. Ecuador 1900-1930. Quito: Hominem Editores / Museo de la Ciudad / Centro Cultural Metropolitano, 2013.

Kristeller, Paul Oskar. "The Modern System of the Arts: A Study in the History of Aesthetics". Journal of the History of Ideas art I. Vol. 12, n. ${ }^{\circ} 4$ (octubre 1951): 496-527. 
. "The Modern System of the Arts: A Study in the History of Aesthetics". Journal of the History of Ideas art II. Vol. 13, n. ${ }^{\circ} 1$ (enero 1952): 17-46.

Malosetti Costa, Laura. Los primeros modernos: Arte y sociedad en Buenos Aires a fines del siglo XIX, Buenos Aires. Buenos Aires: FCE, 2007.

Mera, Juan León. “Conceptos sobre las artes" [1894]. En Teoría del arte en el Ecuador, editado por Edmundo Ribadeneira. Biblioteca Básica del Pensamiento Ecuatoriano. Vol. 31, 291-321. Quito: BCE / CEN, 1987.

- Ojeada histórico-crítica sobre la poesía ecuatoriana desde su época más remota hasta nuestros días. Guayaquil: Ariel, s. f. [1868].

Muratorio, Blanca. "Nación, identidad y etnicidad: imágenes de los indios ecuatorianos y sus imagineros a fines del siglo XIX". En Imágenes e imagineros: representaciones de los indígenas ecuatorianos, siglos XIX y XX, editado por Blanca Muratorio, 109-196. Quito: FLACSO Ecuador, 1994.

Navarro, José Gabriel. La pintura en el Ecuador del XVI al XIX. Quito: Dinediciones, 1991.

O'Doherty, Brian. Inside the White Cube: The Ideology of the Gallery Space, edición ampliada. Berkeley / Londres: University of California Press, 1999.

Oleas, María del Carmen. "El campo del arte en Quito, configuración y cuestionamientos (1966-2008)". Tesis de doctorado. FLACSO Ecuador. 2018.

Pérez, Trinidad. "La construcción del campo moderno del arte en el Ecuador, 18601925: Geopolíticas del arte y eurocentrismo". Tesis de doctorado. Universidad Andina Simón Bolívar, Sede Ecuador (UASB-E). 2012. http:/ / hdl.handle. net/10644/3081/TD028-TECLA-Pérez.

. "La Escuela Nacional de Bellas Artes y el arte moderno en Quito a inicios del siglo XX". En Alma mía. Simbolismo y modernidad. Ecuador 1900-1930, editado y coordinado por Alexandra Kennedy Troya y Rodrigo Gutiérrez Viñuales, 114-122. Quito: Hominem Editores / Museo de la Ciudad / Centro Cultural Metropolitano, 2013.

- "Modos de aprender y tecnologías de la creatividad: el establecimiento de la formación artística académica en Quito: 1849-1930". En Catálogo de la exposición Academias y arte en Quito: 1849-1930, Museo de Arte Colonial, abril-julio del 2017, curadoras Trinidad Pérez y Ximena Carcelén, 17-50. Quito: Casa de la Cultura Ecuatoriana (CCE), 2017.

. "Nace el arte moderno: espacios y definiciones en disputa". En Celebraciones centenarias y negociaciones por la nación ecuatoriana, coordinado por Valeria Coronel y Mercedes Prieto, 23-75. Quito: FLACSO Ecuador, 2010.

. "Raza y modernidad en Las floristas y El sanjuanito de Camilo Egas". En Estudios ecuatorianos: un aporte a la discusión, compilado por Ximena Sosa-Buchholz, 155-165. Quito: FLACSO Ecuador / Abya-Yala, 2006.

Pratt, Mary Louise. Ojos imperiales: literatura de viajes y transculturación. Buenos Aires: Universidad Nacional de Quilmes, 1997.

Rodríguez, Martha. Cultura y política en Ecuador: estudio sobre la creación de la Casa de la Cultura. Quito: FLACSO Ecuador, 2015.

Rolando, Carlos A. Cronología del periodismo ecuatoriano. Pseudónimos de la prensa nacional. Guayaquil: Imprenta y papelería mercantil Monteverde \& Velarde, 1920. 
Salgado, Mireya, y Carmen Corbalán de Celis, "La Escuela de Bellas Artes en el Quito de inicios del siglo XX". Quito: Instituto de la Ciudad, 2012.

Shiner, Larry. La invención del arte: una historia cultural. Barcelona: Paidós, 2004.

Tobar Donoso, Julio. García Moreno y la Instrucción Pública. Quito: Editorial Ecuatoriana, 1940.

Vásquez, María Antonieta. El palacio de la exposición: 1909-1989. Quito: Presidencia de la República / CCE, 1989.

Villacrés, Yesenia. "Revista Caricatura: renovación del campo cultural quiteño por un grupo de 'intelectuales de talento', 1918-1924". Tesis de licenciatura. Pontificia Universidad Católica del Ecuador (PUCE). 2007.

Wallerstein, Immanuel. Abrir las Ciencias Sociales: Informe de la comisión Gulbenkian para la reestructuración de las Ciencias Sociales. Ciudad de México: Siglo XXI Editores, 1999. 


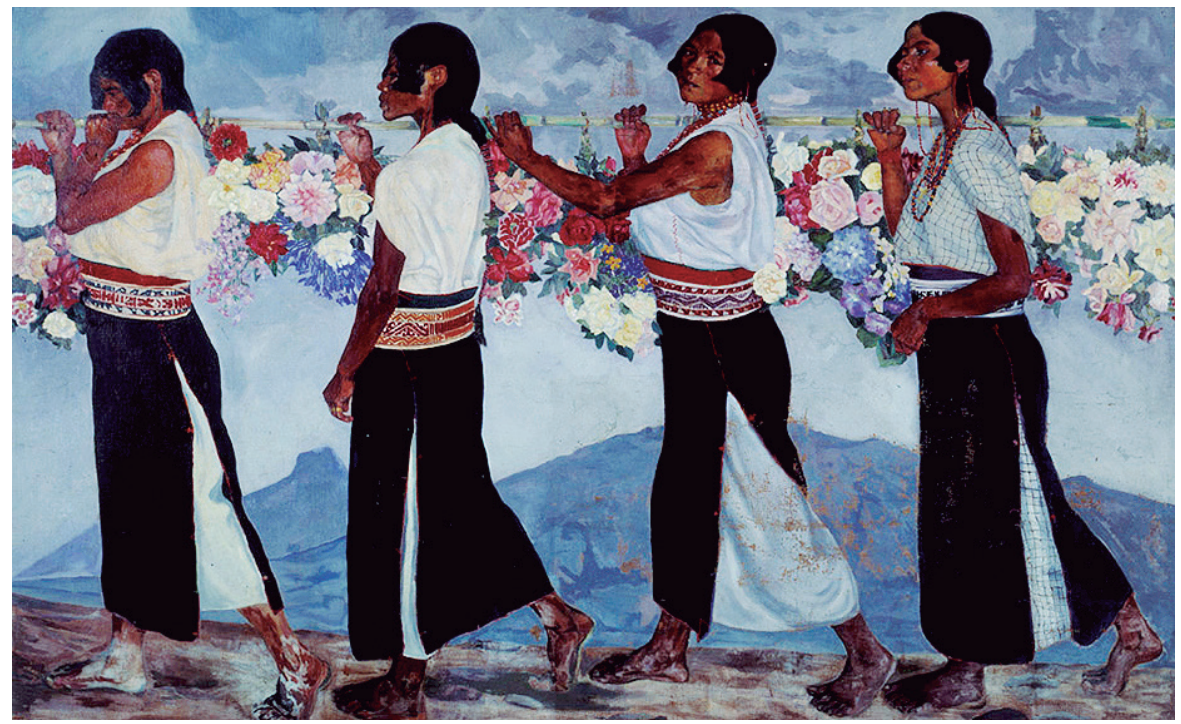

Figura 2. Camilo Egas, Las floristas, óleo sobre tela, 1916. Colección Museo Camilo Egas del Ministerio de Cultura, Quito. Foto: Judy Bustamante. 


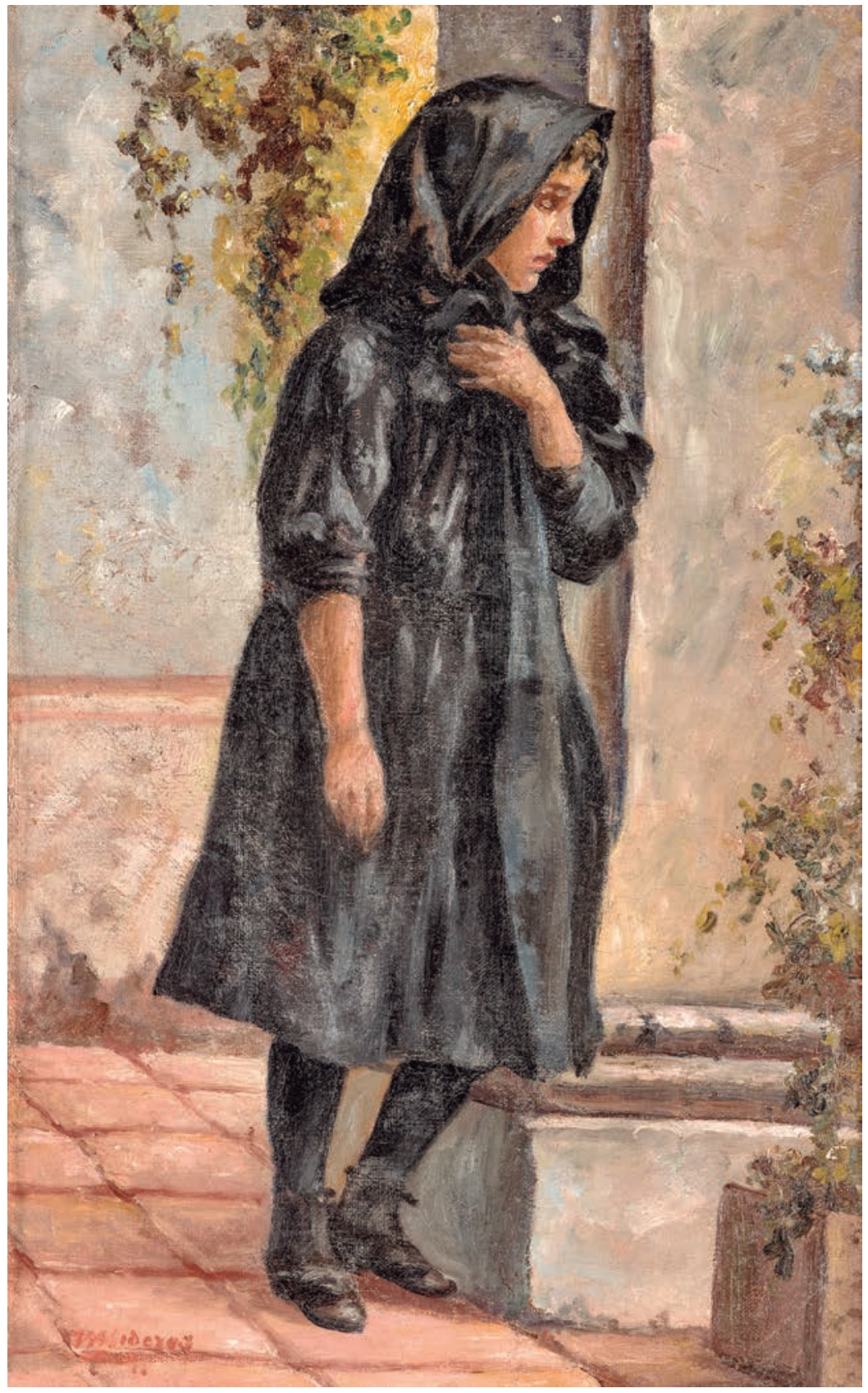

Figura 3. Víctor Mideros, Estrenando orfandad, óleo sobre tela, c. 1916-1918. Colección de Iván Cruz. Pintura de carácter romántico, tal vez como "Hojas que caen", que mereció el Premio Municipal en 1916. Foto: Christoph Hirtz. 


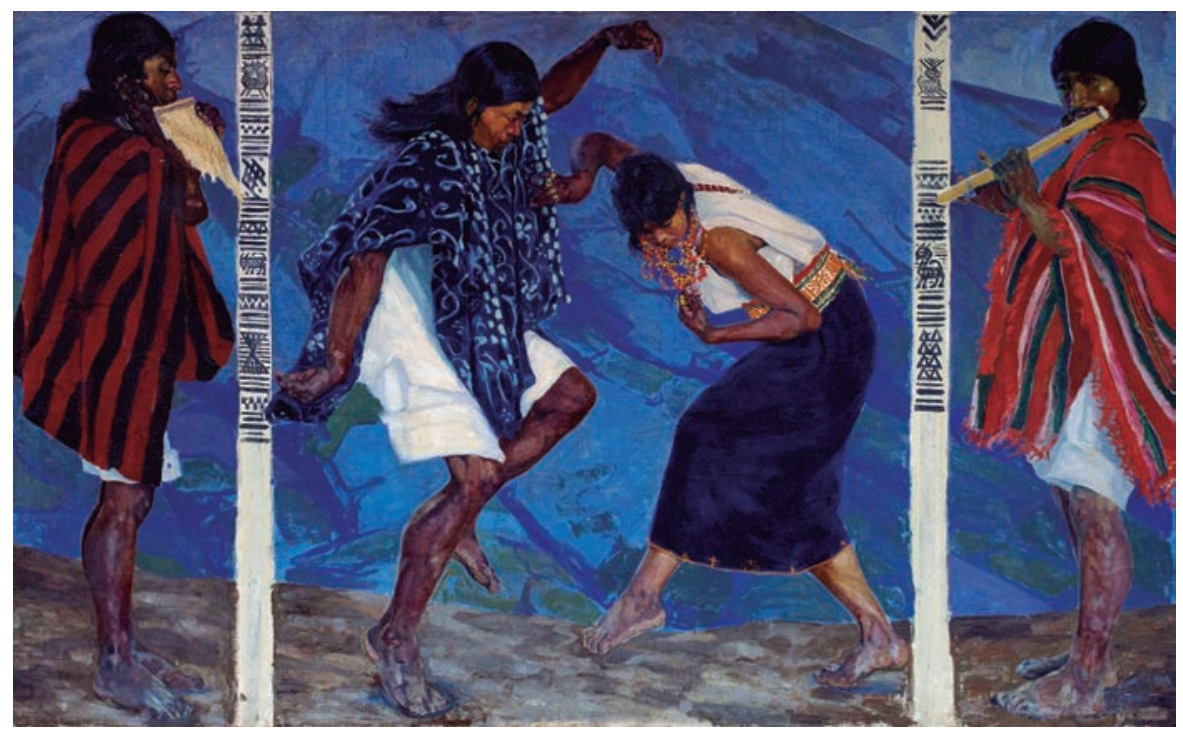

Imagen 5. Camilo Egas, El sanjuanito, óleo sobre tela, 1917. Colección privada. Foto: Juan Diego Pérez. 


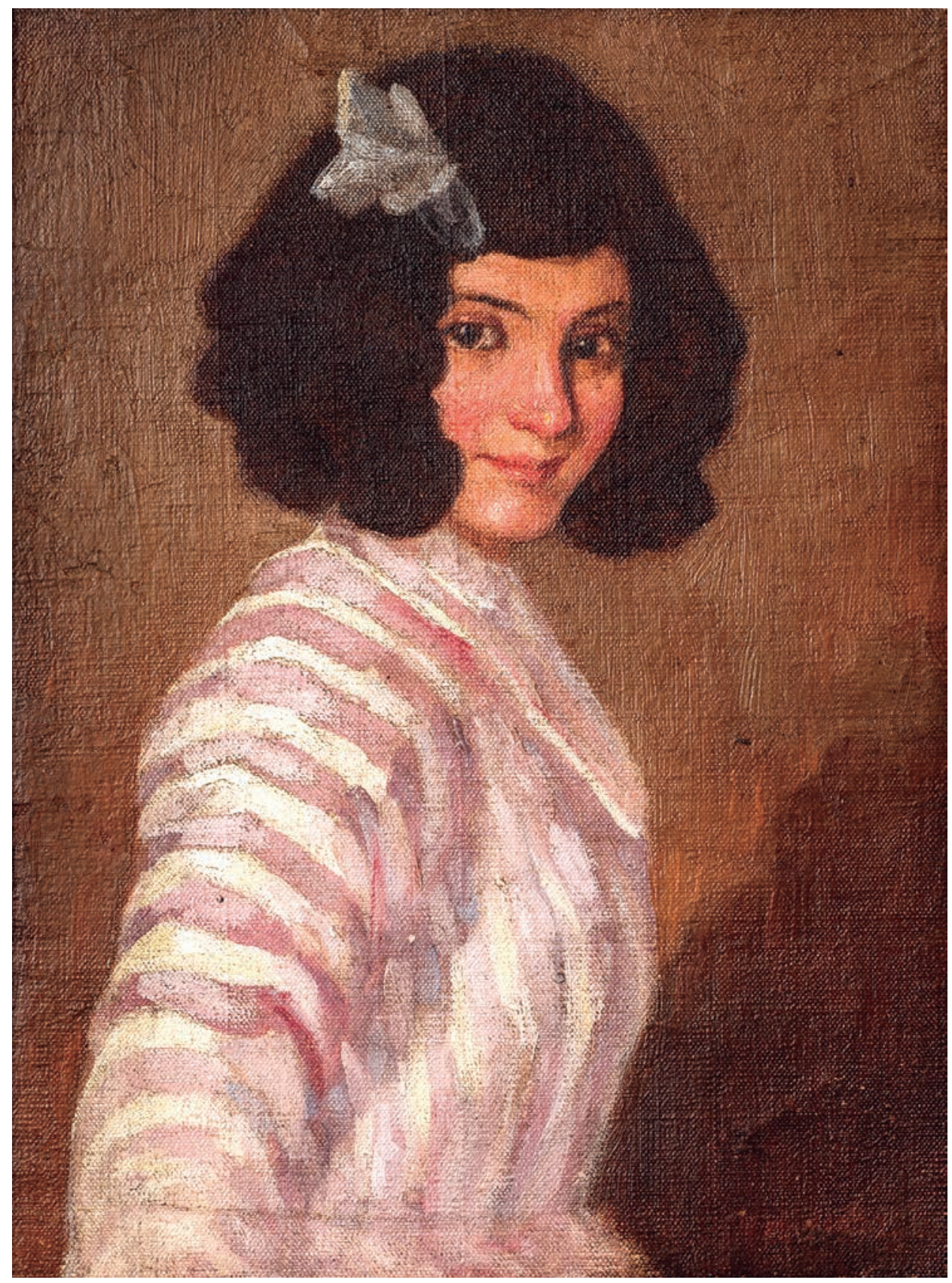

Figura 6. Víctor Mideros, Sin título, óleo sobre tela, c. 1916-1918. Colección privada. Pintura que pudo haber estado entre los retratos que presentó en la VI Exposición Anual de 1918. Foto: Christoph Hirtz. 